\title{
LTP-triggered cholesterol redistribution activates Cdc42 and drives AMPA receptor synaptic delivery
}

\author{
Anna Brachet, ${ }^{1}$ Stephanie Norwood, ${ }^{1}$ Jos F. Brouwers, ${ }^{2}$ Ernest Palomer, ${ }^{1}$ J. Bernd Helms, ${ }^{2}$ Carlos G. Dotti, \\ and José A. Esteban' \\ 'Departamento de Neurobiología, Centro de Biología Molecular "Severo Ochoa," Consejo Superior de Investigaciones Cientificas-Universidad Autónoma de Madrid, \\ 28049 Madrid, Spain \\ 2Department of Biochemistry and Cell Biology, Faculty of Veterinary Medicine, Utrecht University, 3508 Utrecht, Netherlands
}

$\mathrm{N}$ eurotransmitter receptor trafficking during synaptic plasticity requires the concerted action of multiple signaling pathways and the protein transport machinery. However, little is known about the contribution of lipid metabolism during these processes. In this paper, we addressed the question of the role of cholesterol in synaptic changes during long-term potentiation (LTP). We found that $\mathrm{N}$-methyl-D-aspartate-type glutamate receptor (NMDAR) activation during LTP induction leads to a rapid and sustained loss or redistribution of intracellular cholesterol in the neuron. A reduction in

\section{Introduction}

Activity-dependent changes in synaptic function, known as synaptic plasticity, are widely thought as the cellular basis for learning and memory (Bliss and Collingridge, 1993). Longlasting forms of synaptic plasticity, such as long-term potentiation (LTP) and long-term depression in the hippocampus, are now known to rely on the regulated trafficking of $\alpha$-amino-3hydroxy-5-methyl-4-isoxazolepropionic acid (AMPA)-type glutamate receptors (AMPARs) at the postsynaptic membrane in response to the activation of $N$-methyl-D-aspartate (NMDA)type glutamate receptors (NMDARs; Malinow and Malenka, 2002; Kennedy and Ehlers, 2006; Shepherd and Huganir, 2007). Over the last two decades, a plethora of protein-protein interactions and enzymatic activities have been described to orchestrate the intracellular membrane trafficking and targeting of

Correspondence to Carlos G. Dotti: cdotti@cbm.csic.es; or José A. Esteban: jaesteban@cbm.csic.es

Abbreviations used in this paper: ACSF, artificial cerebrospinal fluid; AMPA, $\alpha$-amino-3-hydroxy-5-methyl-4-isoxazolepropionic acid; AMPAR, AMPA-type glutamate receptor; Chol Ox, cholesterol oxidase; cLTP, chemical LTP; CRIB, Cdc42/ Rac interactive binding; DN, dominant negative; GABA, $\gamma$-aminobutyric acid; $G_{A B A} R, G A B A_{A}$ receptor; HEK, human embryonic kidney; $L C$, liquid chromatography; LTP, long-term potentiation; MBCD, methyl- $\beta$-cyclodextrin; mEPSC, miniature excitatory postsynaptic current; mIPSC, miniature inhibitory postsynaptic current; MS, mass spectrometry; NMDA, N-methyl-D-aspartate; NMDAR, NMDA-type glutamate receptor. cholesterol, in turn, leads to the activation of $\mathrm{Cdc} 42$ and the mobilization of GluA 1-containing $\alpha$-amino-3-hydroxy-5methyl-4-isoxazolepropionic acid-type glutamate receptors (AMPARs) from Rab1 1-recycling endosomes into the synaptic membrane, leading to synaptic potentiation. This process is accompanied by an increase of NMDAR function and an enhancement of LTP. These results imply that cholesterol acts as a sensor of NMDAR activation and as a trigger of downstream signaling to engage small GTPase (guanosine triphosphatase) activation and AMPAR synaptic delivery during LTP. these receptors during synaptic plasticity (Huganir and Nicoll, 2013). In contrast, much less is known of the membrane lipid components that participate in this process, particularly as they may act both as sensors of neuronal activity and as mediators of intracellular trafficking.

Cholesterol is an interesting molecule within this context. It participates in multiple cellular functions, including ion channel function, membrane protein trafficking, and intracellular signaling (Dart, 2010; Lippincott-Schwartz and Phair, 2010; Simons and Gerl, 2010). Although cholesterol is a ubiquitous component of eukaryotic cell membranes, it may play distinct functions in the brain because this organ contains $25 \%$ of the body's total cholesterol, despite representing $2 \%$ of the total body's weight (Dietschy and Turley, 2004). The regulation of cholesterol content in the brain is performed in an autonomous manner because plasma lipoproteins are prevented from crossing the blood-brain barrier (Björkhem and Meaney, 2004). Cholesterol levels are regulated in response to strong neuronal activity, linked to excitotoxicity and cellular stress (Sodero et al.,

(C) 2015 Brachet et al. This article is distributed under the terms of an Attribution-NoncommercialShare Alike-No Mirror Sites license for the first six months after the publication date (see http://www.rupress.org/terms). After six months it is available under a Creative Commons License (Attribution-Noncommercial-Share Alike 3.0 Unported license, as described at http:// creativecommons.org/licenses/by-nc-sa/3.0//. 
2011b, 2012). In addition, changes in cholesterol content have been observed during brain aging, as related to neuronal survival (Martin et al., 2008; Sodero et al., 2011a; Ledesma et al., 2012) and cognitive decline (Martin et al., 2014). In fact, it is being increasingly recognized that dysregulation of cholesterol metabolism and homeostasis may have a role in neurological diseases, such as Alzheimer's (Ledesma and Dotti, 2006; Gamba et al., 2012; Suzuki et al., 2013) and Huntington's (Valenza et al., 2005). On the other hand, cholesterol may influence multiple aspects of synaptic transmission (Pfrieger, 2003), both presynaptically, acting on neurotransmitter vesicle fusion (Deutsch and Kelly, 1981; Linetti et al., 2010; Smith et al., 2010; Mercer et al., 2012), and postsynaptically, altering neurotransmitter receptor diffusion (Renner et al., 2009) and endosomal dynamics (Hering et al., 2003; Hou et al., 2008). However, it remains to be established whether cholesterol metabolism is regulated by neuronal activity under physiological conditions, and particularly, what the molecular mechanisms are that link changes in cholesterol to the regulation of synaptic strength during plasticity.

In this study, we investigated the regulation of cholesterol during synaptic plasticity and its contribution to the modification of synaptic function. To this end, we used a combination of pharmacological and molecular tools, together with electrophysiology, biochemistry, and fluorescence imaging. We found that LTP induction triggers a decrease in cholesterol content specifically from intracellular membranes. Cholesterol removal, in turn, leads to the activation of $\mathrm{Cdc} 42$ (cell division control protein 42 homologue) and facilitates the delivery of AMPARs to the synaptic membrane, in a process driven by Rab11-dependent trafficking. Therefore, activity-dependent regulation of cholesterol levels participates in synaptic plasticity by engaging small GTPase signaling and driving AMPAR trafficking to the synaptic membrane.

\section{Results}

LTP induction reduces cholesterol levels from intracellular membranes in neurons It has been recently shown that glutamate-mediated excitotoxicity triggers acute cholesterol loss in hippocampal neurons, and it was suggested that this may reflect the exaggeration of physiological excitatory transmission (Sodero et al., 2012). Here, we tested whether NMDAR activation during synaptic plasticity would also be able to regulate cholesterol levels. We used three complementary approaches: biochemical quantification of endogenous cholesterol, imaging of fluorescently labeled cholesterol derivatives, and monitoring intracellular distribution of a cholesterol binding reporter.

LTP was induced on hippocampal slice cultures using a well-characterized pharmacological approach that mimics biochemical and electrophysiological properties of electrically induced LTP (chemical LTP [cLTP]; Otmakhov et al., 2004; Kopec et al., 2006; Arendt et al., 2014). This pharmacological approach was used to maximize the number of synapses undergoing plasticity. For biochemical quantification of endogenous cholesterol, slices were homogenized just after cLTP induction or after a recovery period of $20 \mathrm{~min}$ and compared with control (untreated) slices. Liquid chromatography (LC)/mass spectrometry (MS) analysis was used to separately measure cholesterol levels in the plasma membrane and microsomal fractions (enriched in intracellular membranes; see Materials and methods). As shown in Fig. 1 A (left-most graph), no significant change was observed in the plasma membrane fraction. In contrast, a rapid and sustained decrease in cholesterol content was observed in intracellular membranes (Fig. 1 A, microsomal fraction, left graph). This decrease required NMDAR activation, as it was blocked when cLTP was induced in the presence of the NMDAR antagonist AP5 (2-amino-5-phosphonopentanoate; Fig. 1 A, +AP5 graphs).

To try and visualize this effect, and also to monitor cholesterol content specifically in neurons, we performed imaging experiments using Bodipy-labeled cholesterol (Hölttä-Vuori et al., 2008; Marks et al., 2008). Bodipy-cholesterol was injected in hippocampal slices in closed proximity to CA1 neurons $24 \mathrm{~h}$ before the experiment. This long incubation time allows labeled cholesterol to equilibrate with the endogenous cholesterol of neurons and reach intracellular membranes (Hölttä-Vuori et al., 2008). Under these conditions, Bodipy-cholesterol was mostly observed in what appeared to be intracellular compartments (Fig. 1 B, inset). Neurons were then identified on the basis of their morphology and localization in the slice. We then imaged Bodipy-cholesterol every 5 min before, during, and after cLTP induction (see Materials and methods). As a control, similar experiments were performed in the presence of AP5, to block NMDARs. We observed that Bodipy-cholesterol fluorescence rapidly decreased upon cLTP induction (Fig. 1, B and C, blue symbols). This decrease was maintained for $\geq 10 \mathrm{~min}$ after the end of the induction. This effect was largely blocked in the presence of AP5, where a slower and less pronounced loss of fluorescence was observed (Fig. 1, B and C, black symbols).

Finally, as a third approach to track intracellular cholesterol content, we monitored the distribution of the cholesterolbinding domain (D4) of perfringolysin O (Shimada et al., 2002), fused to mCherry (Abe et al., 2012). When expressed in hippocampal CA1 neurons, mCherry-D4 displayed a diffuse distribution with the presence of scattered fluorescence clusters (Fig. 1 D, Baseline). These clusters may represent the aggregation of cholesterol-free protein because extraction of cellular cholesterol with methyl- $\beta$-cyclodextrin (MBCD) leads to reduction of diffuse labeling and proliferation of aggregates (Fig. S1 A) that do not generally colocalize with filipin-labeled cholesterol (Fig. S1 B). Upon induction of cLTP in hippocampal slices, mCherry-D4 distribution rapidly changed, with a reduction of diffuse fluorescence and a concomitant increase in cluster intensity (Fig. 1, D and E). These changes were persistent for $\geq 10 \mathrm{~min}$ after cLTP induction. This shift from diffuse to clustered distribution, similar to the one observed upon MBCD cholesterol extraction, suggests that cLTP triggers a significant redistribution of intracellular cholesterol and possibly a net decrease in its content. These combined experiments strongly suggest that LTP induction triggers a rapid and sustained loss or redistribution of cholesterol from intracellular compartments in CA1 hippocampal neurons. 
A

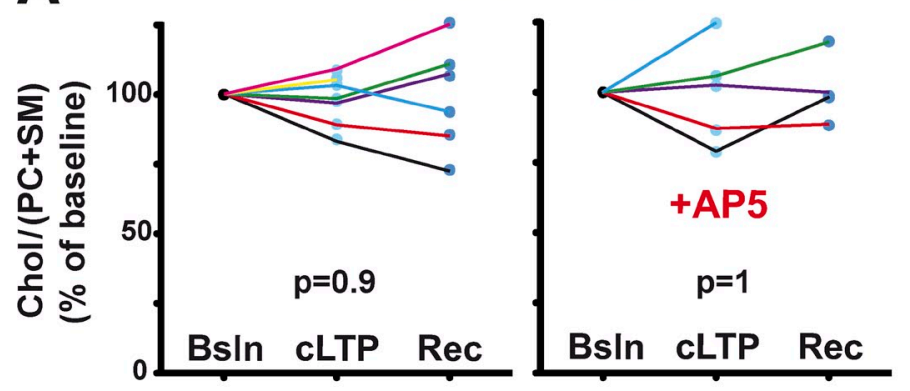

Microsomal fraction

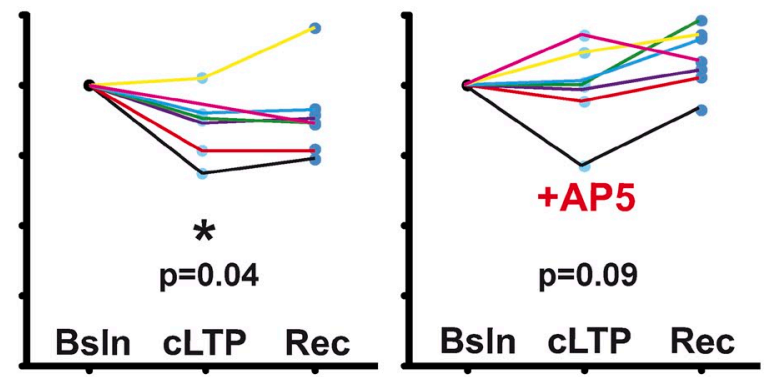

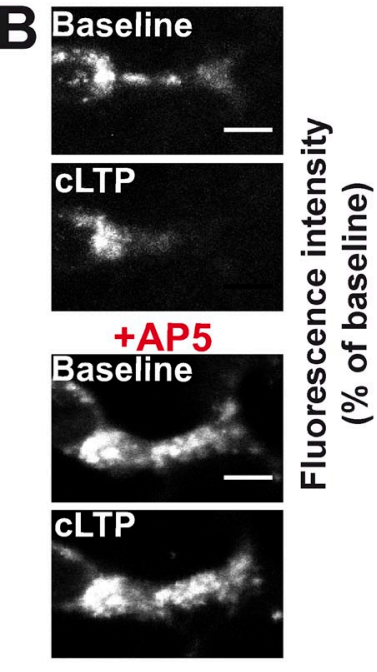

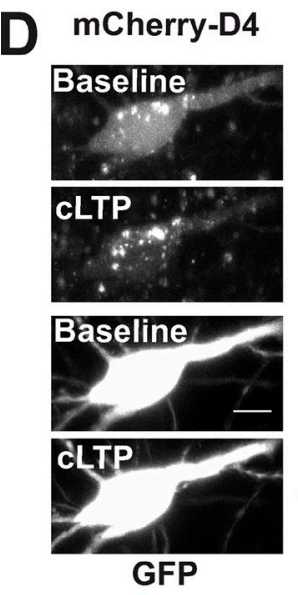

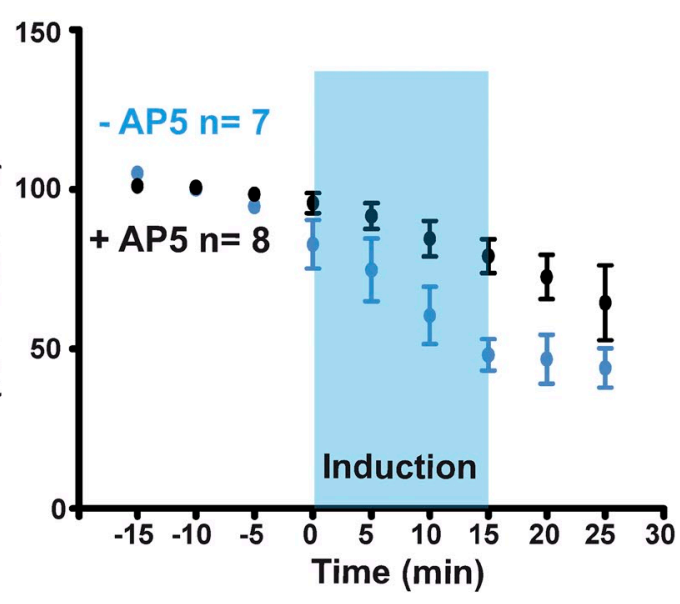
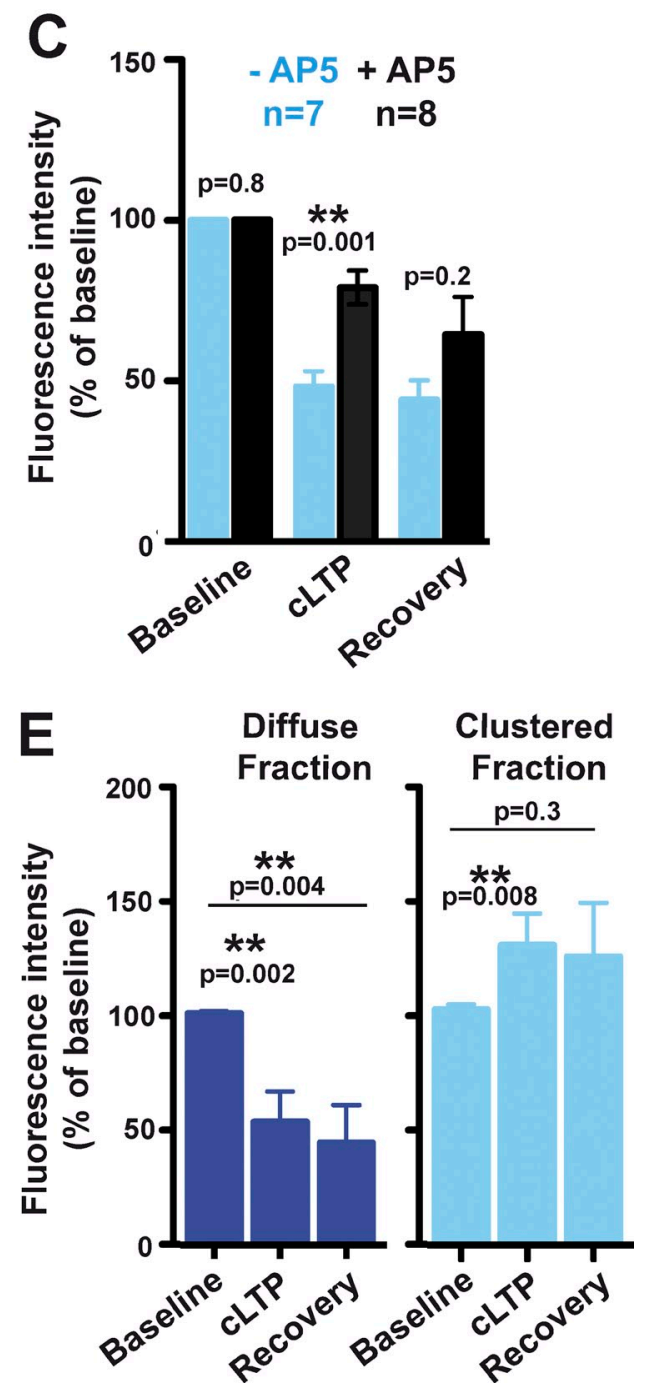

Figure 1. Cholesterol reduction from intracellular membranes after cLTP induction. (A) Quantification of cholesterol content by LC/MS from hippocampal slices immediately after cLTP induction (cLTP), $20 \mathrm{~min}$ recovery after cLTP induction (Rec), or from untreated slices (baseline [Bsln]). Cholesterol (Chol) content was normalized to major phospholipids (phosphocholine [PC] plus sphingomyelin [SM]) and plotted relative to baseline values. Experiments were performed with or without the NMDAR antagonist AP5, as indicated. Symbols connected with lines represent time course experiments performed in parallel. Different lines represent independent experiments. Quantifications were performed from plasma membrane fraction (left) or from microsomal fractions (right). Statistical significance was evaluated with the Kruskal-Wallis test. (B) Quantification of Bodipy-cholesterol fluorescence from hippocampal slices undergoing CLTP induction (blue-shaded area), with or without AP5, as indicated. Fluorescence values are normalized to the mean fluorescence before CLTP induction. $n$ represents the number of cells. Representative images of Bodipy-cholesterol-labeled neurons are shown on the left. (C) Mean values of Bodipy-cholesterol fluorescence immediately at the end of the cLTP induction period (cLTP) and after 10-min recovery, from the time course shown in B. The $p$-value was determined with the Mann-Whitney test. $n$ represents the number of cells. (D) Diffuse and clustered mCherry-D4 fluorescence was quantified (see Materials and methods) from hippocampal slices undergoing CLTP induction (blue-shaded area). Fluorescence values are normalized to the mean fluorescence before cLTP induction. $n$ represents the number of cells. Left shows representative images of a CAl neuron expressing $\mathrm{mCherry-D4}$ (top) and EGFP (bottom), before (Baseline) and after 15-min cLTP induction. (E) Mean values of mCherry-D4 diffuse or clustered fluorescence immediately before (Baseline), at the end of the cLTP induction period (cLTP), or after $10 \mathrm{~min}$ of recovery, from the time course shown in D. The p-value was determined with the Mann-Whitney test. $n$ represent the number of cells. Error bars show means \pm SEM. Bars, $10 \mu \mathrm{m}$. 
Figure 2. Effect of cholesterol removal on synaptic function. (A and B) Quantification of cholesterol content of hippocampal slices treated with cholesterol oxidase (Chol Ox) or methyl- $\beta$-cyclodextrin (MBCD) from plasma membrane fraction (A) or from microsomal fraction (B). Values are normalized to untreated (control) slices. $n$ represents number of independent experiments. Statistical significance is calculated according to the Wilcoxon test for slices treated in parallel. (C and D) Input resistance (C) and whole-cell capacitance (D) from hippocampal slices treated as indicated. $n$ represents the number of cells. Statistical significance is calculated according to the Mann-Whitney test. (E) Paired-pulse facilitation (PPF) ratios from whole-cell synaptic responses evoked by stimulation with different interstimulus intervals $(50,100,200$, and $400 \mathrm{~ms})$. Hippocampal slices were treated as indicated. Representative traces at 50-ms interstimulus interval are shown above the graph. Bars: (vertical) $50 \mathrm{pA}$; (horizontal) $50 \mathrm{~ms}$. (F) Mean ratio of synaptic responses mediated by AMPARs and $G_{A B A} R s$ (AMPA/GABA ratio). Representative traces are shown above the histogram. Bars: (vertical) 50 pA; (horizontal) $10 \mathrm{~ms}$. $n$ represents the number of cells. Statistical significance is calculated according to the Mann-Whitney test. (G) Cumulative distribution of mEPSC amplitude from dissociated neuronal cultures treated with Chol Ox or untreated controls, as indicated. Mean mEPSC amplitude from the same data is plotted as a histogram in the inset. $n$ represents number of miniature responses recorded from four cells for each condition. Representative traces are shown above the graphs. Bars: (horizontal) $1 \mathrm{~s}$; (vertical) 10 pA. (H) Similar to G for mIPSC amplitudes. Bars: (horizontal) $1 \mathrm{~s}$; (vertical) $50 \mathrm{pA}$. Error bars show means \pm SEM.
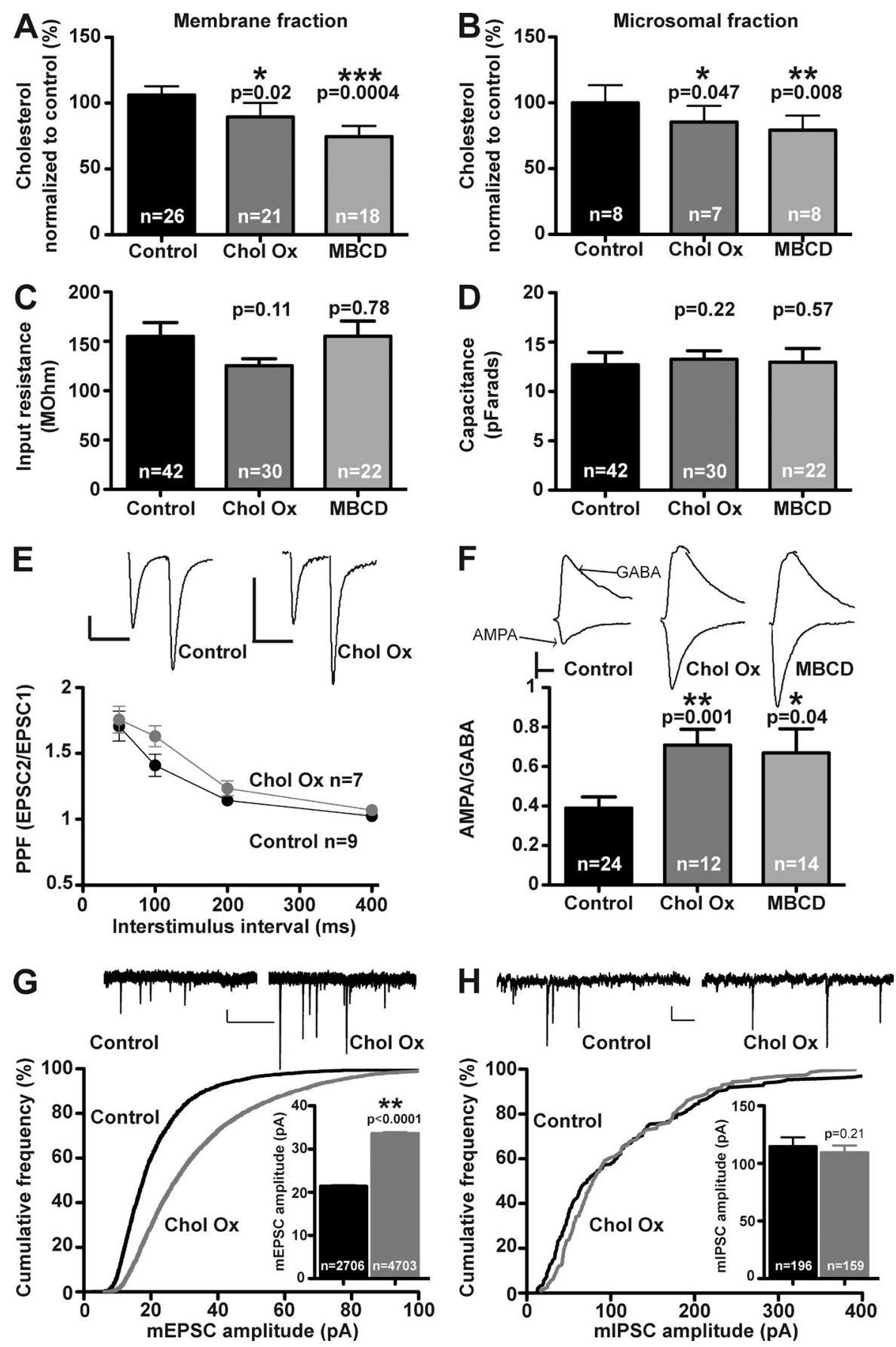

\section{Cholesterol removal enhances excitatory synaptic transmission}

After observing that LTP induction leads to a rapid decrease in cholesterol content in CA1 neurons, we decided to test whether an acute cholesterol loss may in turn affect synaptic function. To this end, we used pharmacological approaches, rather than slower genetic interventions or inhibitors of enzymatic activities, to bypass compensatory effects and/or accumulation of intermediary products (Kotti et al., 2006). Endogenous cholesterol was reduced by short time applications $(30 \mathrm{~min})$ of MBCD (10 mM) or cholesterol oxidase (Chol Ox) enzyme $(10 \mathrm{U} / \mathrm{ml})$. These two manipulations offer complementary information to control for potential nonspecific effects because
MBCD is only partially specific for cholesterol (Ohtani et al., 1989) but does not generate additional metabolites, whereas Chol Ox is very specific for cholesterol but generates $\mathrm{H}_{2} \mathrm{O}_{2}$ and a ketone derivative of cholesterol as byproducts. As shown in Fig. 2 A, both protocols produced a moderate but significant decrease of cholesterol levels in hippocampal slices, as probed by a fluorescence enzymatic assay. This decrease was stable $1 \mathrm{~h}$ after the end of the treatment (Fig. S2 A). Of note, these manipulations initially target plasma membrane cholesterol, but they produced a similar reduction of cholesterol from intracellular membranes (Fig. 2 B), probably because of the extensive exchange between these two pools of cholesterol (Zidovetzki and Levitan, 2007). Importantly, this pharmacological reduction in 
cholesterol from intracellular membranes was quantitatively similar to the one observed upon cLTP induction (compare Fig. $1 \mathrm{~A}$ and Fig. $2 \mathrm{~B}$ ).

To evaluate the effect of cholesterol decrease on synaptic function, we measured CA3-to-CA1 responses in hippocampal slices using whole-cell electrophysiological recordings. Importantly, MBCD or Chol Ox treatments did not affect passive membrane properties of the cell, such as input resistance (Fig. 2 C, reflecting cell-wide ion channel conductances and membrane integrity), and cell size, as reported by whole-cell capacitance (Fig. 2 D). In addition, cholesterol removal did not change presynaptic properties of excitatory transmission (as assayed by paired-pulse facilitation; Fig. 2 E), or general cell viability (MTT assay; Fig. S2 B). Therefore, acute cholesterol removal of this magnitude (20-30\%) does not appear to have any general toxic effect or physiological change in neurons from hippocampal slices.

We then measured evoked AMPAR- and $\gamma$-aminobutyric acid $(\mathrm{GABA}) \mathrm{A}\left(\mathrm{GABA}_{\mathrm{A}}\right)$ receptor-mediated responses in CA1 pyramidal neurons. Ratios of these responses were used for normalization to compare potential differential effects on these synapses. As shown in Fig. 2 F, AMPA/GABA ratios of synaptic responses significantly increased after MBCD or Chol Ox treatments compared with untreated neurons. These results suggest that cholesterol removal produces a differential effect at these synapses. To dissect specific functional changes at excitatory versus inhibitory synapses, we recorded miniature excitatory postsynaptic currents (mEPSCs) and miniature inhibitory postsynaptic currents (mIPSCs) from primary neuronal cultures (see Materials and methods). As shown in Fig. 2 G, the treatment with Chol Ox produced a marked increase in mEPSC amplitude, without any significant effect on mIPSC amplitude (Fig. $2 \mathrm{H}$ ). All together, these results indicate that cholesterol reduction specifically enhances AMPAR-mediated synaptic transmission.

\section{Cholesterol removal induces the delivery of} new GluA1 at synapses

The combined observation that LTP induction reduces cholesterol levels and that cholesterol reduction enhances AMPARmediated synaptic responses, suggests that the activity-dependent cholesterol removal may participate in the mechanisms leading to synaptic potentiation during LTP. A hallmark of NMDARdependent LTP is the synaptic delivery of GluA1-containing AMPARs (Hayashi et al., 2000; Passafaro et al., 2001; Shi et al., 2001; Boehm et al., 2006; but see also Granger et al., 2013). Therefore, we first tested whether AMPARs of specific subunit composition are inserted at synapses in response to cholesterol removal. To this end, we expressed individual EGFP-tagged AMPAR subunits. When overexpressed, these subunits form homomeric receptors, which can be detected at synapses by their inward rectification properties (Hayashi et al., 2000; Shi et al., 2001; in the case of GluA2, we used the rectifying unedited version R607Q).

First, GluA1-EGFP was expressed in organotypic slice cultures for $48 \mathrm{~h}$, and synaptic delivery was quantified as an increase in the ratio of the evoked postsynaptic current at $-60 \mathrm{mV}$ relative to the current at $+40 \mathrm{mV}$ (rectification index $=\mathrm{I}_{-60} / \mathrm{I}_{+40}$ ), in the presence of the NMDAR antagonist AP5. GluA1-EGFPexpressing neurons display little inward rectification (Fig. 3 A, compare first and third columns), in agreement with the observation that GluA1-containing AMPARs are not efficiently inserted at synapses, unless driven by strong synaptic stimulation or activation of specific signaling pathways associated to LTP induction (Hayashi et al., 2000; Boehm et al., 2006). In contrast, we found that cholesterol reduction in GluA1-EGFP-expressing neurons markedly increased the rectification index (Fig. $3 \mathrm{~A}$, compare third and fourth columns). This result strongly suggests that cholesterol removal induces synaptic delivery of GluA1 AMPARs.

Recombinant GluA2 receptors reach synapses constitutively and, therefore, can be used to monitor the cycling population of AMPARs (Shi et al., 2001). As expected, when GluA2(R607Q)EGFP was expressed, the rectification index was significantly increased compared with nontransfected cells (Fig. 3 A, compare first and fifth columns), indicating the presence of the recombinant receptor at the synapse. Interestingly, when cholesterol was decreased in GluA2(R607Q)-EGFP-expressing neurons, this increase in rectification was strongly attenuated (Fig. 3 A, compare fifth and sixth columns). This result indicates that the proportion of newly inserted (rectifying) GluA2(R607Q)-EGFP to endogenous (not rectifying) AMPARs is lower in cholesteroldepleted neurons. Of note, this assay reports the relative contribution of recombinant (rectifying) to endogenous (nonrectifying) receptors. Therefore, the observation that cholesterol removal increases rectification when the recombinant receptor is homomeric GluA1 and decreases it when the recombinant receptor is homomeric GluA2(R607Q), strongly suggests that cholesterol removal specifically triggers the synaptic insertion of GluA1containing AMPARs. Importantly, the treatment with Chol Ox did not change the rectification index in the absence of recombinant receptors (Fig. $3 \mathrm{~A}$, compare first and second columns), indicating that cholesterol removal does not alter the intrinsic rectification properties of endogenous AMPARs.

To confirm these results on endogenous AMPARs, we performed a double immunostaining of surface and total GluA1 receptors in dissociated hippocampal neurons (Fig. 3 B). Surface receptors were labeled with an anti-N terminus antibody under nonpermeabilized conditions, and total receptors were labeled with an anti-C terminus antibody after permeabilization (see Materials and methods). Here, acute cholesterol removal led to an increase of surface versus total GluA1 expression in dendrites when compared with control (Fig. 3, B and C), in agreement with our electrophysiology data (Fig. 3 A). Of note, total GluA1 expression was not affected by cholesterol removal, as probed by Western blotting on dissociated neurons and organotypic hippocampal cultures (Fig. 3, D and E). Collectively, these results indicate that cholesterol removal enhances excitatory synaptic transmission by inducing the delivery of new GluA1-containing AMPARs at the postsynaptic membrane.

Synaptic potentiation induced by cholesterol removal is mediated by Rab11

To ascertain the delivery route for AMPARs, we assessed the involvement of Rab11-dependent trafficking, which mediates 

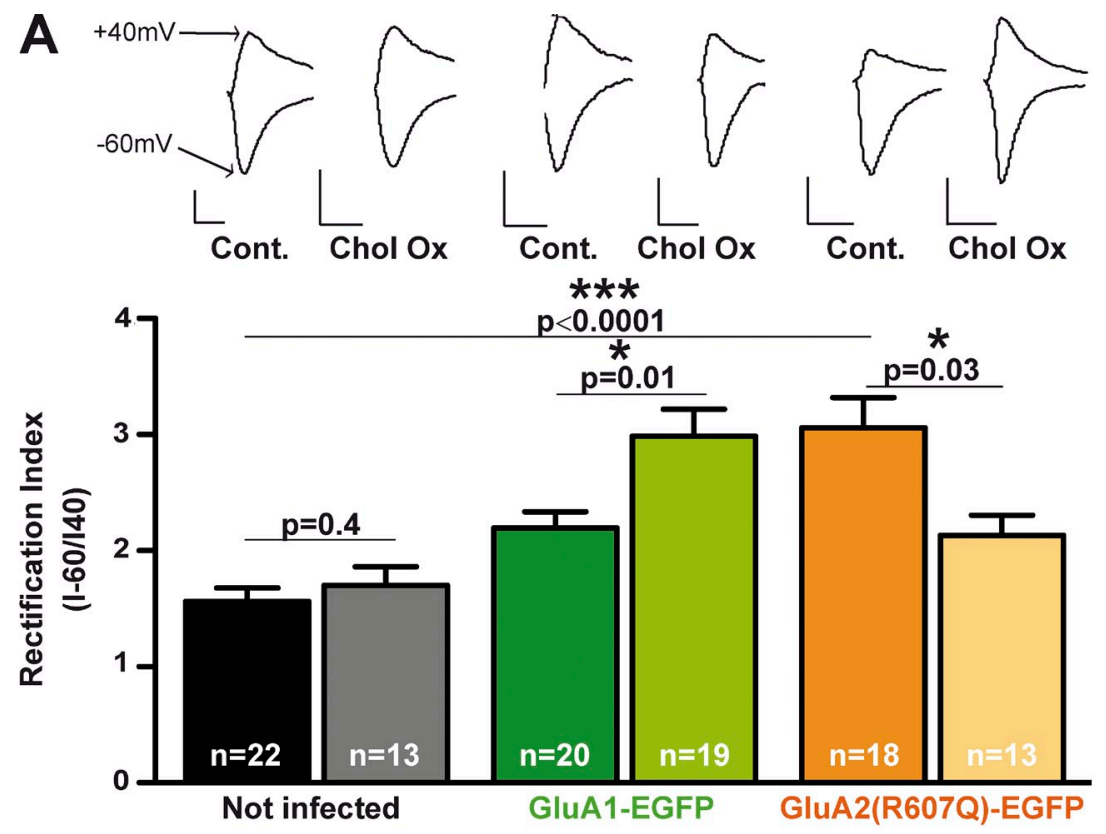

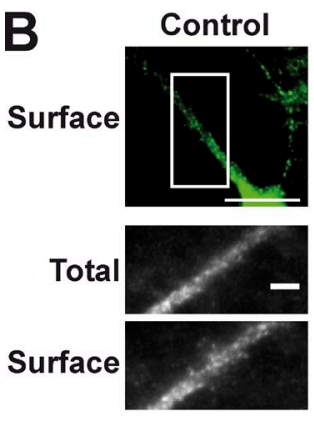

D
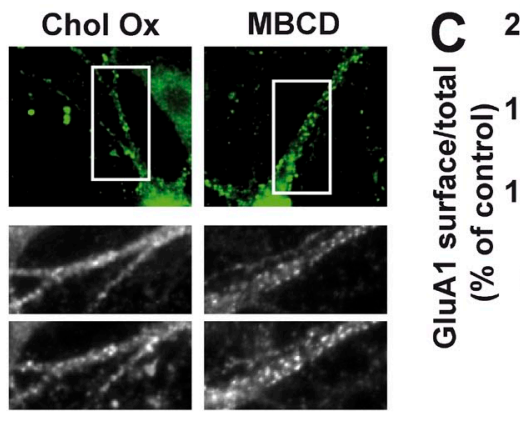

Dissociated neurons
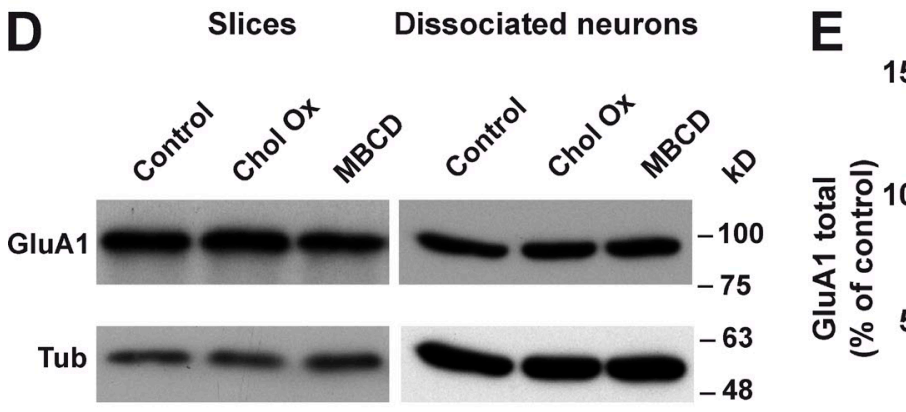

Figure 3. Cholesterol removal induces surface delivery and synaptic insertion of GluA1 AMPARs. (A) AMPAR-mediated responses were recorded at -60 and $+40 \mathrm{mV}$, from hippocampal slices expressing GluA1-EGFP, GluA2(R607Q)-EGFP, or not infected, with or without Chol Ox treatment, as indicated. The rectification index was calculated as the ratio of responses at these holding potentials $\left(I_{-60 \mathrm{mV}} / \mathrm{I}_{+40 \mathrm{mV}}\right)$. Representative traces are shown above the histogram. Bars: (vertical) 50 pA; (horizontal) $10 \mathrm{~ms}$. $n$ represents the number of cells. The p-value was determined using the Mann-Whitney test. (B) Representative images of primary hippocampal neuronal cultures treated as indicated and immunostained for surface and total GluAl expression. Bottom images represent zoomed-in images from top boxes. Bars: (top) $20 \mu \mathrm{m}$; (bottom) $5 \mu \mathrm{m}$. (C) Quantification of surface over total expression of GluA1 from dendritic branches as the ones shown in B. Values are normalized to untreated neurons. $n$ represents number of cells out of three independent experiments. Statistical significance was calculated using the Mann-Whitney test. (D) Western blot analysis of GluAl levels from hippocampal slices or from dissociated primary neuronal cultures, treated as indicated. Tub, tubulin. (E) Quantification of total GluAl levels from $n$ independent experiments as the one shown in D. Error bars show means \pm SEM.

the activity-dependent delivery of GluA1-containing AMPARs from intracellular compartments into synapses during LTP (Park et al., 2004; Brown et al., 2007). To evaluate the role of Rab11 in AMPAR synaptic delivery upon cholesterol removal, we used a well-characterized dominant-negative (DN) version of Rab11 (Rab11-S25N; Ullrich et al., 1996). Evoked AMPARmediated synaptic responses were simultaneously recorded from nearby pairs of CA1 neurons expressing EGFP-Rab11-DN and uninfected neurons (Fig. 4 A, scheme). As previously published (Gerges et al., 2004), overexpression of EGFP-Rab11-DN 
A

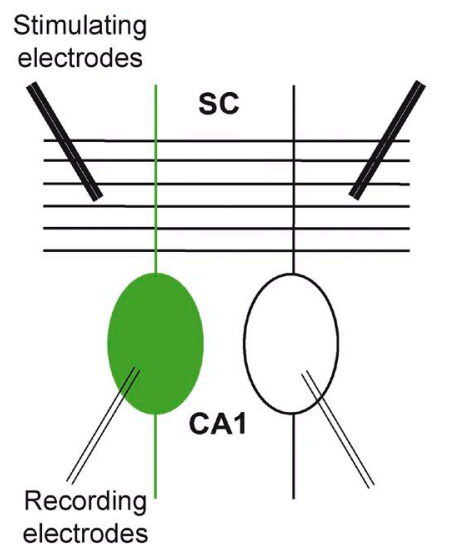

electrodes
B
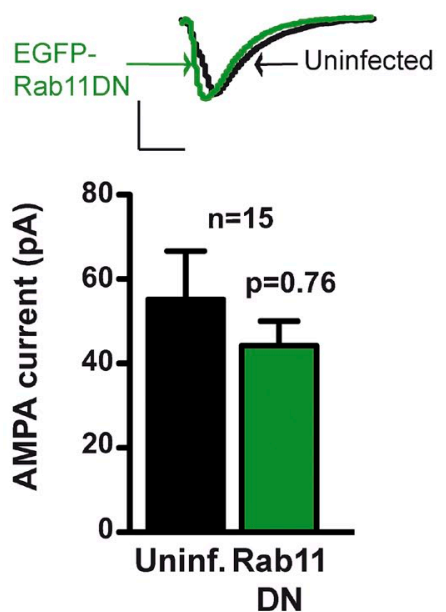

D


G

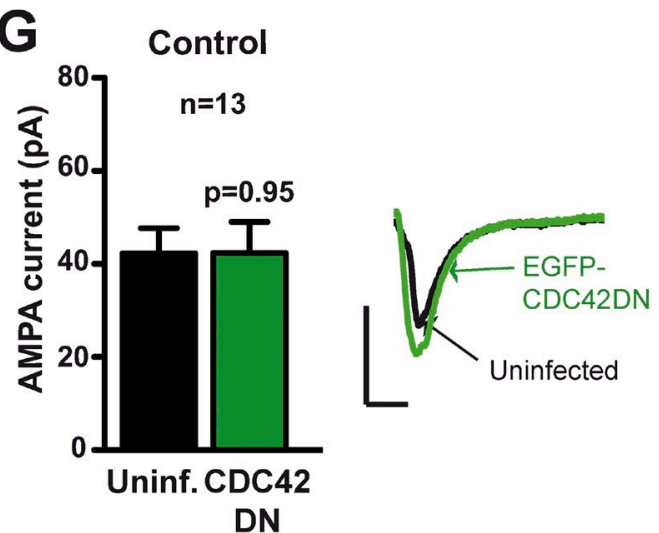

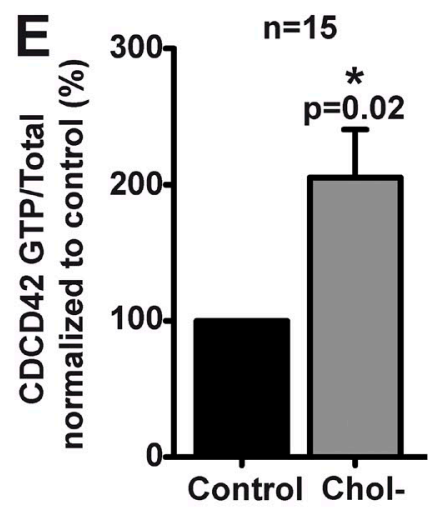

$\mathrm{H}$

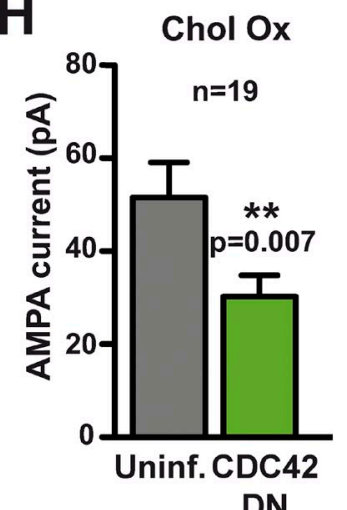

C Chol Ox
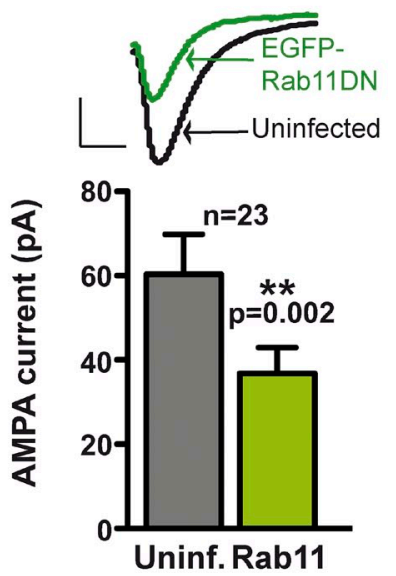

DN

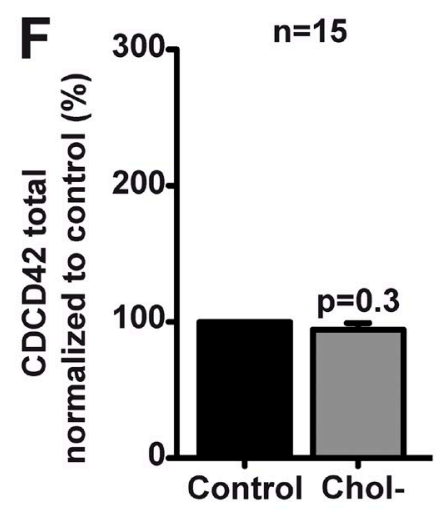

Figure 4. Synaptic potentiation induced by cholesterol removal requires Rab11 and Cdc42 activity. (A) Schematic representation of the experimental configuration for paired, simultaneous recordings of AMPAR synaptic responses from infected (green) and uninfected (white) CAl neurons. SC, Schaffer collaterals. (B and C) Mean AMPAR-mediated synaptic responses from pairs of uninfected (Uninf.) or Rab1 1-DN-EGFP-expressing neurons, from untreated hippocampal slices (B) or treated with Chol Ox (C). Representative traces are shown above the histogram. Bars: (vertical) 50 pA; (horizontal) $10 \mathrm{~ms}$. Statistical significance is calculated according to the Wilcoxon test. (D) Pull-down from organotypic slice culture extracts with GST-Pak3-CRIB under control conditions and after cholesterol removal by Chol Ox or MBCD treatment. Total and GTP-bound Cdc42 was detected by immunoblotting with specific antibodies to $\mathrm{Cdc} 42$. Tubulin was used as a loading control. (E and F) Quantification of active Cdc42-GTP (E) or total Cdc42 (F) levels from slices treated for cholesterol removal or from untreated controls, as indicated. Results from Chol Ox and MBCD treatments were similar, and they have been pooled together. The ratios of GTP-bound and total Cdc42 were normalized to untreated controls. $n$ represents the number of pairwise comparisons between treated and nontreated slices. Statistical significance is calculated according to the Wilcoxon test. (G and H) Similar to B and C for EGFP-Cdc42-DN-expressing neurons. Error bars show means \pm SEM.

has no significant effect on synaptic AMPAR currents under basal conditions (Fig. 4 B). In contrast, neurons overexpressing EGFP-Rab11-DN exhibit smaller AMPAR currents than their neighboring uninfected neurons upon cholesterol removal (Fig. 4 C). These results indicate that Rab11-DN blocks the potentiation of AMPAR currents produced by acute cholesterol 

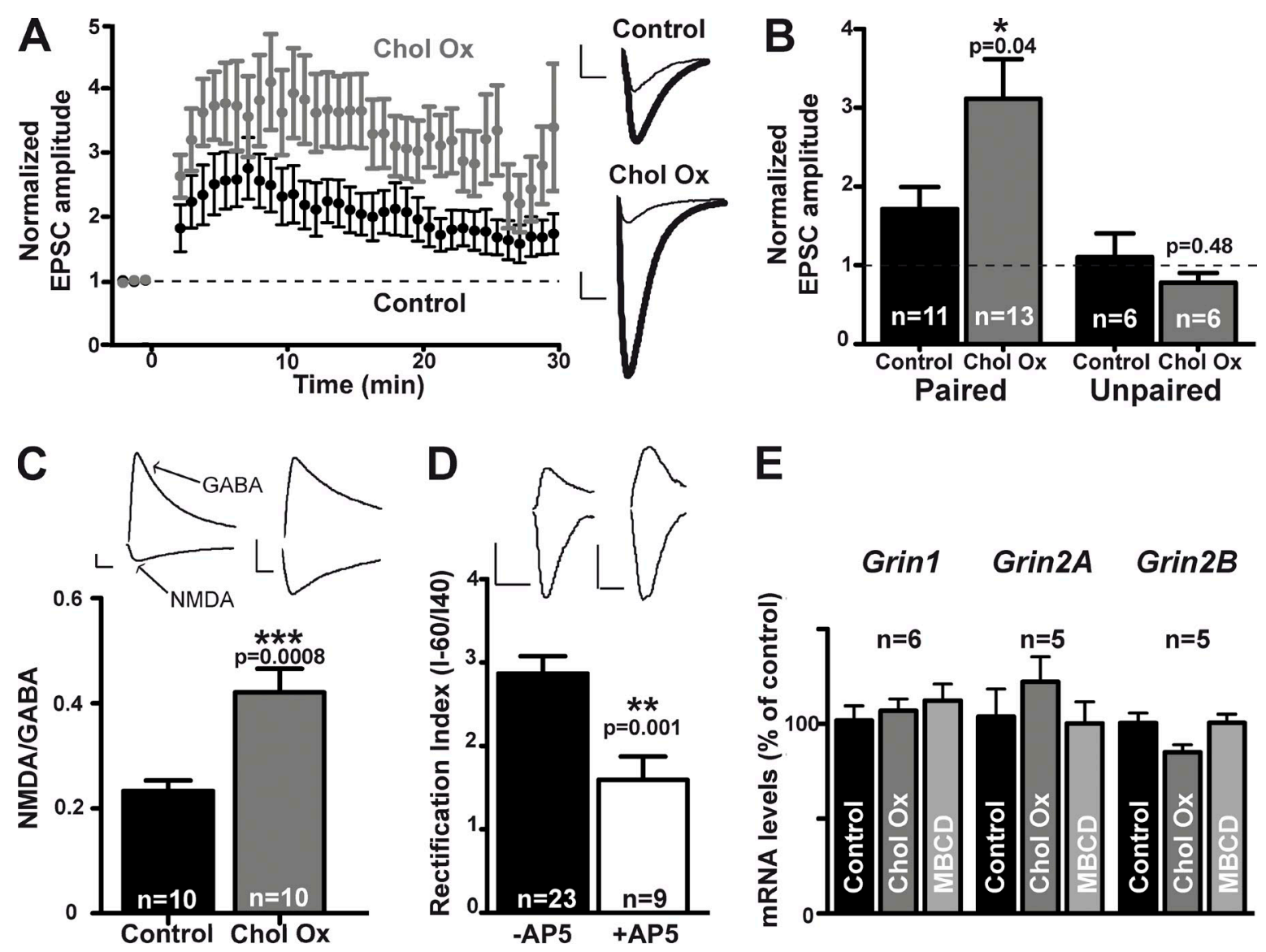

$\mathrm{E}$
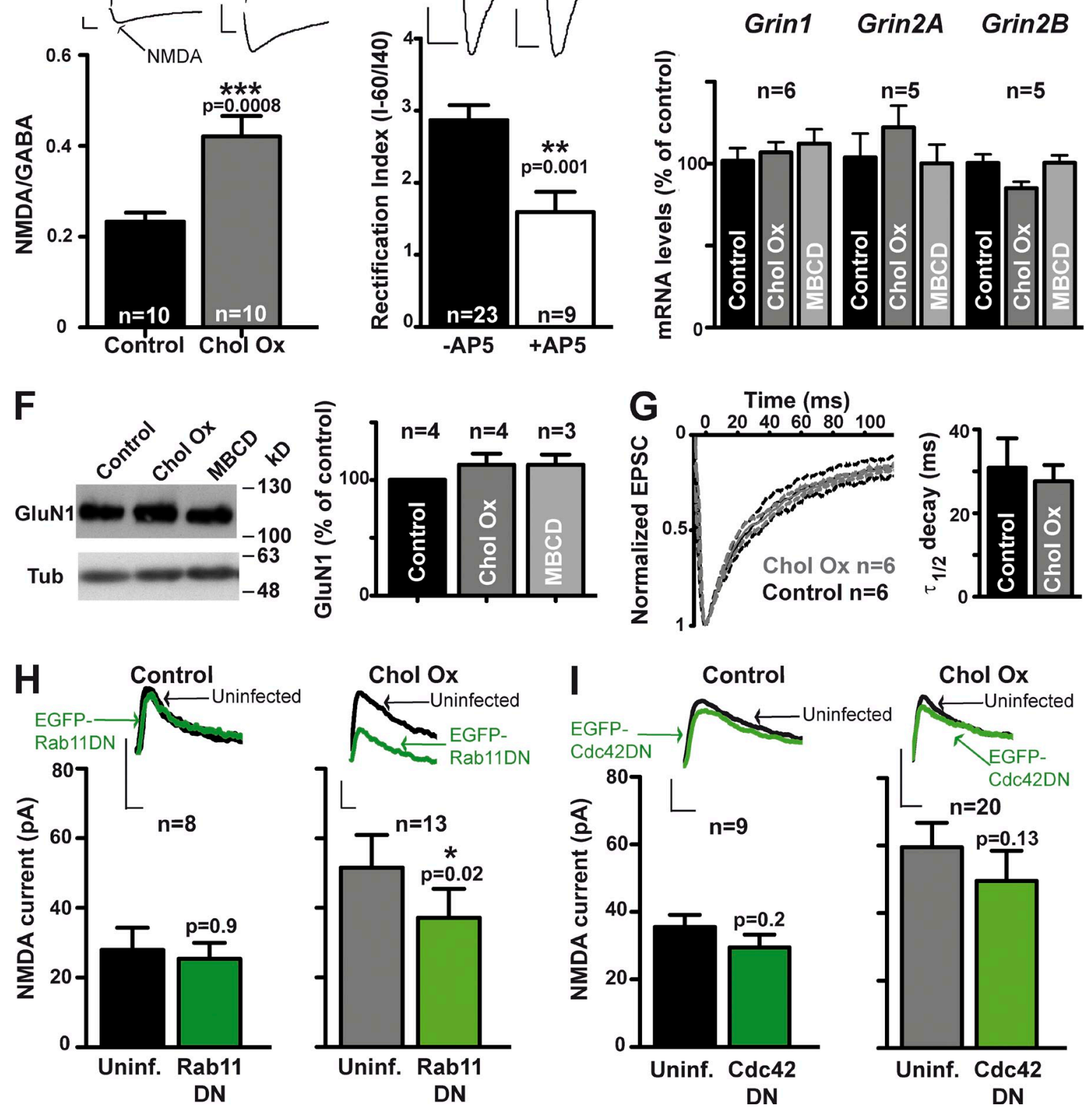

Figure 5. Cholesterol removal enhances NMDAR synaptic currents and LTP. (A) Time course of normalized AMPAR-mediated synaptic responses before and after LTP induction, from control slices or slices treated with Chol Ox. LTP was induced at time $=0$ min. Sample traces recorded before (thin line) and after (thick line) LTP induction are shown on the right. Bars: (vertical) 50 pA; (horizontal) 10 ms. (B) Quantification of mean synaptic potentiation from paired 
depletion. Thus, we conclude that Rab11-dependent trafficking mediates the synaptic delivery of AMPARs triggered by cholesterol removal.

Cholesterol depletion activates Cdc42, which mediates AMPAR synaptic potentiation

It has been recently shown that LTP induction triggers the activation of the small GTPase Cdc42 (Murakoshi et al., 2011) and that this activation is required for synaptic potentiation (Kim et al., 2014). We therefore tested whether a similar mechanism may be operating upon cholesterol reduction. We first evaluated whether cholesterol removal alters Cdc42 activation in hippocampal slices. To this end, we treated hippocampal slices with Chol Ox or with MBCD, as described for Fig. 2. Then, the amount of active (GTP bound) Cdc42 was measured with a standard pull-down assay with GST-Pak3-Cdc42/Rac interactive binding (CRIB; Hansen and Nelson, 2001). As shown in Fig. 4 (D and E), cholesterol reduction produced a significant activation of $\mathrm{Cdc} 42$ in hippocampal extracts, without altering total levels of Cdc42 (Fig. 4 F).

Then, we tested whether Cdc42 activation was required for AMPAR synaptic delivery triggered by cholesterol removal. Similar to the experiments in Fig. 4 (B and C), we expressed a well-characterized DN form of Cdc42 (T17N; Hansen and Nelson, 2001) in CA1 hippocampal neurons and measured its effect on synaptic transmission with and without cholesterol removal. As shown in Fig. 4 G, Cdc42-DN did not alter AMPAR synaptic transmission under control conditions. In contrast, in Chol Ox-treated slices, Cdc42-DN significantly depressed AMPAR responses (Fig. $4 \mathrm{H}$ ). These results imply that $\mathrm{Cdc} 42-$ DN blocks the enhancement of AMPAR responses induced by cholesterol removal. Therefore, we conclude that AMPAR synaptic potentiation requires $\mathrm{Cdc} 42$ activation.

\section{Cholesterol reduction enhances NMDAR currents and facilitates LTP}

Given the parallelisms between AMPAR synaptic delivery triggered by LTP induction and by cholesterol removal, we decided to test whether cholesterol content affects this form of synaptic plasticity. As in our previous experiments, slices were pretreated with Chol Ox for $30 \mathrm{~min}$, and LTP was induced in CA1 neurons with a standard pairing protocol (Hayashi et al., 2000). As shown in Fig. 5 (A and B), LTP induction significantly increased AMPAR-mediated responses in both cholesterol-depleted and untreated neurons. Nevertheless, the reduction in cholesterol content enhanced LTP expression twofold compared with untreated neurons. Therefore, these data indicate that reduced levels of cholesterol facilitate NMDARdependent LTP.

These results were counterintuitive because we had observed that cholesterol removal induces AMPAR synaptic delivery in a process mechanistically similar to LTP (involving the GluA1 subunit and Rab11 trafficking). Therefore, we expected that LTP and synaptic potentiation induced by cholesterol removal may occlude each other. On the other hand, it has also been shown that oxysterols may directly modulate NMDR function (Linsenbardt et al., 2014). We then tested whether cholesterol removal was affecting NMDAR-mediated synaptic responses and, in this manner, may alter LTP induction. To this end, we performed similar experiments to those shown in Fig. $2 \mathrm{~F}$, but measuring NMDA/GABA ratios (without $\mathrm{Mg}^{2+}$ and in the presence of CNQX to block AMPAR responses). As shown in Fig. $5 \mathrm{C}$, cholesterol removal produced a significant increase in NMDA/GABA ratio. Given our previous observation that cholesterol reduction does not alter GABA transmission (Fig. $2 \mathrm{H}$ ), this result indicates that cholesterol removal induces an increase of NMDAR synaptic currents, as it does for AMPAR responses.

Because cholesterol removal enhances NMDAR function and facilitates LTP, we then hypothesized that this may contribute to the AMPAR synaptic delivery we had observed. Therefore, we tested whether GluA1 synaptic delivery upon cholesterol removal requires NMDAR activation. GluA1 delivery was examined by monitoring inward rectification (as described for Fig. 3 A) while blocking NMDARs during the acute removal of cholesterol. We found that application of $100 \mu \mathrm{M}$ AP5 completely blocked the increase in rectification produced by cholesterol removal (AP5 was present $1 \mathrm{~h}$ before and during cholesterol removal; Fig. 5 D). Therefore GluA1 synaptic delivery triggered by cholesterol removal requires NMDAR activity. Altogether, these data indicate that cholesterol reduction enhances NMDAR synaptic responses and facilitates the synaptic delivery of AMPARs in an LTP-like process.

and unpaired pathways from the last 10 min of the time course shown in A (for the unpaired pathway, one stimulating electrode is turned off during LTP induction). The $p$-value was determined with the Mann-Whitney test. n, number of cells. (C) Mean NMDA/GABA ratios calculated from synaptic responses recorded in the presence of $C N Q X$ and in the absence of $\mathrm{Mg}^{2+}$, at $-60 \mathrm{mV}$ for NMDARs and at $0 \mathrm{mV}$ for GABA $\mathrm{A}_{\mathrm{A}}$. Hippocampal slices were treated with Chol Ox or left untreated (control). Representative traces are shown above the histograms. $n$ represents the number of cells. Statistical significance is calculated according to the Mann-Whitney test. (D) Rectification experiments similar to the ones described in Fig. 3 A, from slices expressing GluA1-EGFP and treated with $\mathrm{Chol} \mathrm{Ox}$ in the presence of AP5 (NMDAR inhibitor). Data from slices without AP5 are replotted from Fig. 3 A. $n$ represents number of cells, and p-value was determined with the Mann-Whitney test. Representative traces are shown above the histogram. Bars: (vertical) 50 pA; (horizontal) $10 \mathrm{~ms}$. (E) mRNA analysis by quantitative RT-PCR for Grin 1, Grin2A, and Grin2B (GluN1, GluN2A, and GluN2B, respectively) from slices treated with Chol Ox or $M B C D$. Values are normalized to untreated slices. $n$ represents number of independent experiments. (F) Western blot analysis of GluN1 expression from whole extracts of hippocampal slices treated with Chol Ox or MBCD. Values are normalized to untreated slices. $n$ represents number of independent experiments. A representative blot is shown on the left. Tub, tubulin. (G, left). Mean trace of NMDAR response, obtained from the same recordings as in $C$, normalized to its peak amplitude from control and Chol Ox-treated slices. SEM is plotted for each trace as thin dashed lines. (right) Mean half-decay time $\left(t_{1 / 2}\right)$ of NMDA responses from the same data plotted on the left. (H) Mean NMDAR-mediated synaptic responses from pairs of uninfected (Uninf.) or EGFP-Rab 1 1-DN-expressing neurons, from untreated hippocampal slices (left) or treated with Chol Ox (right). Representative traces are shown above the histogram. Bars: (vertical) $50 \mathrm{pA}$; (horizontal) $10 \mathrm{~ms}$. Statistical significance is calculated according to the Wilcoxon test. (I) Similar to H, with pairs of uninfected and Cdc42-DN-expressing neurons. Error bars show means \pm SEM. 
Figure 6. Effect of cholesterol addition on LTP and NMDAR synaptic responses. (A) Time course of normalized AMPAR-mediated synaptic responses before and after LTP induction, from slices treated with the MBCD-cholesterol (Chol/MBCD) complex or vehicle control $(0.1 \%$ ethanol), as indicated. LTP was induced at time $=0 \mathrm{~min}$, by pairing presynaptic $3-\mathrm{Hz}$ stimulation (300 pulses) with postsynaptic depolarization $(0 \mathrm{mV})$. Sample traces recorded before (thin line) and after (thick line) LTP induction are shown above the graph. (B) Quantification of mean synaptic potentiation from the last $10 \mathrm{~min}$ of the time course shown in $A$. The $p$-value was determined with the Mann-Whitney test. $n$, number of cells. (C) Time course of normalized NMDARmediated synaptic responses (recorded in the presence of CNQX and in the absence of $\mathrm{Mg}^{2+}$ ), during addition of $\mathrm{MBCD}$-cholesterol (area shaded in magenta). Representative traces before (thin line) and after MBCDcholesterol treatment (thick line) are shown above the graph. Bars: (horizontal) $10 \mathrm{~ms}$; (vertical) $10 \mathrm{pA}$. (D) Quantification of mean synaptic depression from the last $10 \mathrm{~min}$ of the time course shown in C. The p-value was determined with the Wilcoxon test, comparing before and after MBCD-cholesterol treatment for each cell. $n$ represents number of cells. Error bars show means \pm SEM.

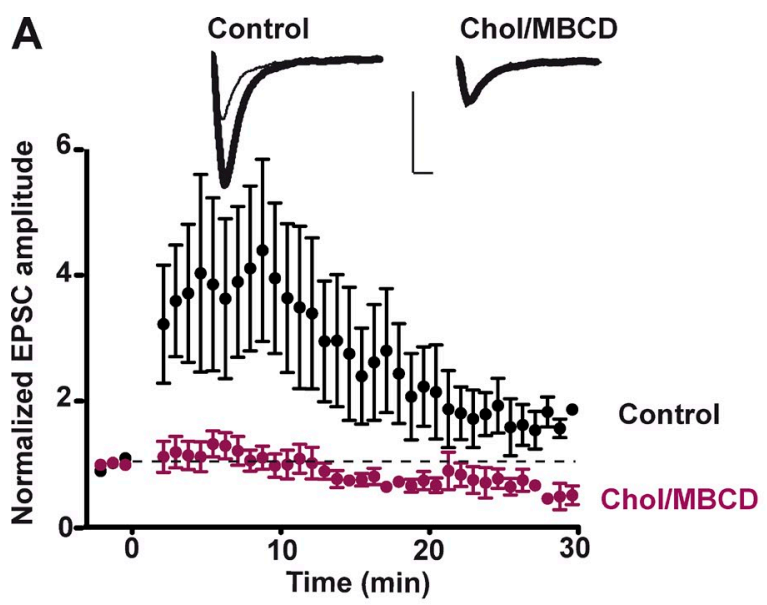

B

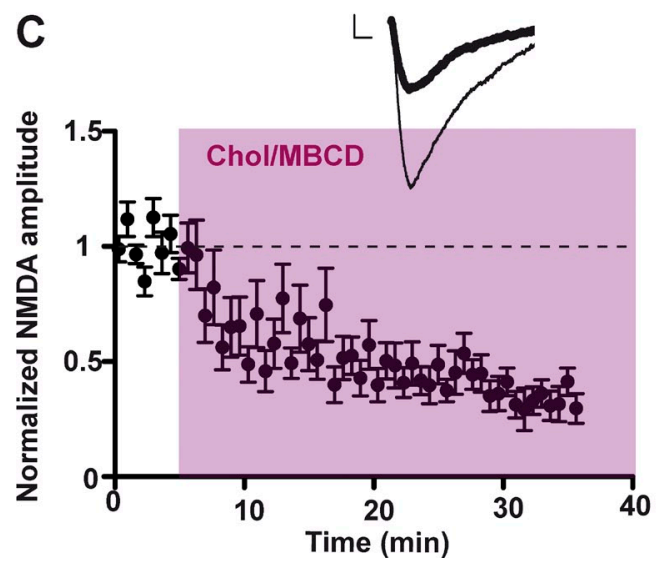

Synaptic potentiation of NMDARs by cholesterol removal requires Rab11-dependent trafficking but not Colc42 activation

These last results suggest that cholesterol, besides being regulated downstream from NMDAR activation (Fig. 1), also acts as upstream regulator of NMDAR function. We then investigated the mechanisms by which cholesterol removal enhances NMDAR function.

It has been previously shown that cholesterol reduction triggers TrkB activation (Martin et al., 2008), and TrkB signaling has been linked to enhanced NMDAR transcription (Caldeira et al., 2007). Therefore, we tested whether cholesterol removal from hippocampal slices would alter NMDAR mRNA levels. As shown in Fig. 5 E, RT-PCR analysis from hippocampal slices treated with Chol Ox did not detect any significant changes in mRNA levels for NMDAR subunits (Grin1, Grin2A, and Grin2B, corresponding to GluN1, GluN2A, and GluN2B proteins, respectively). In addition, Western blot analysis also failed to detect changes in NMDAR protein expression upon cholesterol removal (Fig. 5 F).

Changes in the subunit composition of synaptic NMDARs may also have important consequences for synaptic plasticity (Liu et al., 2004). To address this issue, we evaluated the kinetics of NMDAR synaptic responses because currents mediated by GluN2A- or GluN2B-containing NMDARs are characterized by different decay times (Monyer et al., 1994). As shown in Fig. 5 G, the decay times of NMDA responses were not significantly altered by cholesterol removal, arguing against changes in subunit composition.

We then asked whether potentiation of NMDAR responses induced by cholesterol removal was mediated by Rab11dependent trafficking and/or Cdc42 activity, as was the case for AMPARs. As shown in Fig. 5 (H and I), neither Rab11-DN nor Cdc42-DN altered NMDAR synaptic transmission under control conditions. In contrast, Rab11-DN (Fig. $5 \mathrm{H}$ ), but not Cdc42DN (Fig. 5 I), depressed NMDAR responses after cholesterol removal. These results suggest that NMDAR synaptic potentiation induced by cholesterol reduction is mediated by Rab11dependent trafficking, but it does not require Cdc42 activity.

\section{Cholesterol addition impairs LTP}

Our results shown here suggest that cholesterol loss may be an intrinsic mechanism mediating LTP expression. To test this hypothesis, we aimed to prevent cholesterol reduction during LTP induction by applying a saturating amount of cholesterol in complex with MBCD. MBCD-cholesterol inclusions readily exchange cholesterol with cellular membranes (Christian et al., 1997) and, therefore, will buffer potential changes in cholesterol levels. We then performed LTP experiments, similar to Fig. 5 A, comparing slices treated with MBCD-cholesterol versus vehicle control (0.1\% ethanol). As shown in Fig. 6 (A and B), LTP induction significantly increased AMPAR-mediated responses in controls neurons. In contrast, LTP was completely absent in cholesterol-treated neurons. 
This result supports the interpretation that cholesterol removal is a necessary step for LTP expression. However, NMDAR function itself may be regulated by cholesterol, as it has been shown for oxysterols (Linsenbardt et al., 2014). To test this possibility, we acutely added MBCD-cholesterol while monitoring NMDAR synaptic responses. As shown in Fig. 6 C, cholesterol addition produced a rapid and pronounced rundown of NMDA responses, which stabilized at $\sim 50 \%$ depression. Although this result does not necessarily contradict the interpretation that cholesterol removal is required for LTP expression, we cannot rule out that NMDAR depression is at least partially responsible for the LTP impairment shown in Fig. 6 (A and B).

\section{Discussion}

In this study, we propose that cholesterol has a dual function during synaptic plasticity (Fig. 7, schematic representation). On the one hand, a reduction in intracellular cholesterol constitutes an intermediate step downstream from LTP induction, linking NMDAR signaling with the activation of $\mathrm{Cdc} 42$ and the synaptic trafficking of AMPARs (Fig. 7, right elements). On the other hand, cholesterol levels modulate NMDAR trafficking and, in this manner, are upstream regulators of LTP induction (Fig. 7, left elements). The role of cholesterol as a downstream mediator of LTP is based on three main lines of evidence. First, induction of NMDAR-dependent LTP produces a sustained decrease or redistribution in cholesterol content, preferentially from intracellular compartments. Second, pharmacological reduction of cholesterol levels leads to the activation of $\mathrm{Cdc} 42$. Third, this activation is required for the delivery of AMPARs into the synaptic membrane, in a process mediated by Rab11-dependent trafficking. The role of cholesterol as an upstream regulator of NMDAR function would be mechanistically different. It also relies on Rab11-dependent trafficking but is independent from Cdc42 signaling.

Diverse (and often conflicting) results have been reported for the synaptic effects of manipulating cholesterol levels. Strong depression of basal synaptic transmission and LTP impairment has been observed upon cholesterol reduction with cyclodextrin (Frank et al., 2008). In contrast, LTP enhancement and no effect on basal transmission were reported with a statin inhibitor of cholesterol biosynthesis (Mans et al., 2010). However, the opposite effect (LTP impairment) was observed using a different statin (Kotti et al., 2006). We cannot aim to explain this divergent literature. Nevertheless, we do want to emphasize that this study stems from the observation of an endogenous reduction of cholesterol upon synaptic plasticity induction. As for the pharmacological manipulations, we have obtained consistent results using cholesterol extraction methods (cyclodextrin treatment) as well as enzymatic degradation (Chol $\mathrm{Ox}$ ), and we report the actual cholesterol reduction obtained with these methods. Finally, by evaluating AMPAR-, NMDAR-, and $\mathrm{GABA}_{\mathrm{A}}$ receptor $\left(\mathrm{GABA}_{\mathrm{A}} \mathrm{R}\right)$-mediated currents, as well as LTP expression, in hippocampal slices, we are able to present a coherent scenario, in which activity-dependent changes in cholesterol mediate intracellular signaling for AMPAR synaptic delivery, and further modulate NMDAR function.

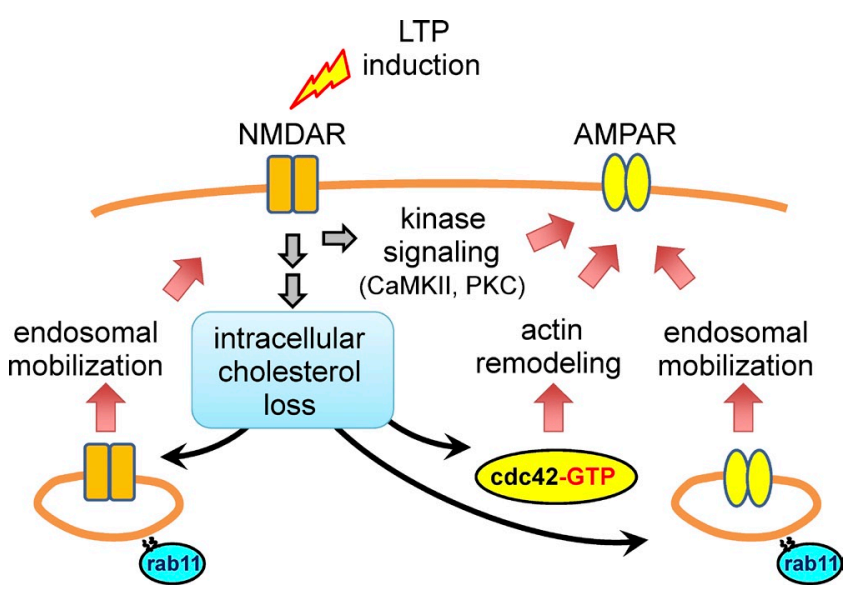

Figure 7. Schematic representation of cholesterol regulation during LTP and participation in synaptic plasticity mechanisms. NMDAR activation upon LTP induction leads to the loss of cholesterol from intracellular membranes. This in turn leads to the activation of $\mathrm{Cdc} 42$ and the mobilization of Rabl1-dependent trafficking. These two events, together with further downstream signaling from NMDARs, are required for AMPAR synaptic delivery and potentiation of synaptic transmission (right side of the cartoon). In contrast, enhancement of NMDAR responses is mediated by Rab 11 but does not require $\mathrm{Cdc} 42$ activation (left side of the cartoon).

An important insight from this work is that NMDAR activation during LTP induction triggers a rapid reduction in intracellular cholesterol. Several neurodegenerative disorders such as Huntington's (Valenza et al., 2010) or Alzheimer's disease (Ledesma and Dotti, 2006; Gamba et al., 2012), as well as ageing (Ledesma et al., 2012), have been associated with alterations in cholesterol metabolism. Reductions in cholesterol levels have also been observed upon excitotoxic stimuli (Sodero et al., 2012). Nevertheless, to our knowledge, this is the first study of an acute modulation of neuronal cholesterol induced by physiological synaptic activity, namely, LTP induction. The mechanism responsible for this cholesterol change remains to be determined, but it is intriguing that the reduction occurred preferentially at intracellular membranes (as reported with both biochemical and imaging methods). Of note, intracellular compartments contain only a small fraction of total cellular cholesterol (Lange et al., 1989). Therefore, changes in cholesterol turnover (Sodero et al., 2012) as well as subcellular redistribution (Hölttä-Vuori et al., 2002) may be responsible for this acute reduction in intracellular cholesterol.

In this study, we have also addressed the functional consequences of this reduction in cholesterol. Intracellular cholesterol is preferentially associated to recycling endosomes (Hao et al., 2002, 2004), and it has been proposed that this pool of cholesterol favors intracellular retention of raft-associated proteins (Mayor et al., 1998). Therefore, it is tempting to speculate that a localized depletion of cholesterol will favor the mobilization of internalized proteins. This may be related to the Rab11dependent synaptic enhancement that we have observed for both AMPARs and NMDARs. Nevertheless, the synaptic targeting of these two types of receptors is not mechanistically equivalent. Thus, AMPAR synaptic potentiation required both Rab11 and $\mathrm{Cdc} 42$ activity, suggesting that besides mobilization of recycling endosomes, this process engages additional signaling 
events (Kim et al., 2014). In contrast, NMDAR potentiation upon cholesterol removal may represent a more passive consequence of mobilizing an extrasynaptic pool of NMDARs. In the case of AMPAR synaptic delivery, the involvement of Cdc42 is particularly interesting because this small GTPase is activated upon LTP induction (Murakoshi et al., 2011) and is required for synaptic potentiation and spine structural plasticity (Kim et al., 2014). The mechanisms leading to Cdc42 activation upon cholesterol removal are not completely clear. They may be related to the displacement of Cdc42 from lipid rafts (Fessler et al., 2004; Jaksits et al., 2004). Interestingly, concomitant Cdc42 activation and mobilization of Rab11 recycling endosomes has been observed in hepatic cells upon cholesterol removal (Xie et al., 2011). Additionally, reduction in cholesterol levels has been linked to the activation of the phosphoinositide 3-kinase pathway (Martin et al., 2008, 2011), which may in turn lead to $\mathrm{Cdc} 42$ activation via phosphatidylinositol $(3,4,5)$ trisphosphate-sensitive Cdc42 GEFs, such as Vav2 and Vav3 (Aoki et al., 2005).

In conclusion, cholesterol reduction downstream from NMDAR activation would trigger two separate events: mobilization of intracellular AMPARs via Rab11-dependent synaptic trafficking and activation of $\mathrm{Cdc} 42$ for actin remodeling and structural plasticity. These two events are necessary for AMPAR synaptic potentiation (Fig. 7). Nevertheless, full LTP expression would require additional signaling events triggered downstream from NMDARs because pharmacological removal of cholesterol is not sufficient to induce AMPAR synaptic potentiation without concomitant NMDAR activation (Fig. 7). Altogether, our data reveal the existence of a dynamic interplay between cholesterol levels in neurons and synaptic activity and provide a mechanistic link between activity-dependent cholesterol changes, AMPAR trafficking, and synaptic plasticity.

\section{Materials and methods}

\section{Ethics statement}

All biosafety procedures and animal care protocols were approved by the bioethics committee from the Consejo Superior de Investigaciones Cientificas and were performed according to the guidelines set out in the European Community Council Directives (86/609/EEC).

\section{Neuronal cultures and recombinant protein expression}

Organotypic hippocampal slice cultures were prepared as previously described (Gähwiler et al., 1997). In brief, hippocampal slices are prepared from young rats (postnatal days 5-7), placed in culture on semipermeable membranes in a medium containing $20 \%$ horse serum, $1 \mathrm{mM}$ l-glutamine, $1 \mathrm{mM} \mathrm{CaCl}_{2}, 2 \mathrm{mMMgSO}_{4}, 1 \mathrm{mgl}^{-1}$ insulin, $0.0012 \%$ ascorbic acid, $30 \mathrm{mM}$ Hepes, $13 \mathrm{mM}$ D-glucose, and $5.2 \mathrm{mM} \mathrm{NaHCO}_{3}$, and maintained at $35.5^{\circ} \mathrm{C}$. Culture medium was replaced with a fresh one every 2-3d. The slices were used at 5-6 $d$ in vitro for most experiments and $\leq 8 \mathrm{~d}$ for LTP experiments. Primary dissociated hippocampal neurons were prepared as previously described (Goslin and Banker, 1989). In brief, hippocampi are extracted from rat fetuses at embryonic day 19 , and dissociated neurons are plated on glass coverslips coated with $1 \mathrm{mg} / \mathrm{ml}$ of poly--lysine. Cultures are maintained at $37^{\circ} \mathrm{C}$ in Neurobasal medium (Gibco) supplemented with B27 (Gibco) and glutamine and used at $14 \mathrm{~d}$ in vitro.

DNA constructs for the expression of GluA1-EGFP and GluA2-EGFP were generated in the laboratory of R. Malinow (University of California, San Diego, San Diego, CA). In these constructs, EGFP is fused in frame immediately downstream from the signal peptide of GluA1 and GluA2 (Shi et al., 2001). DN forms of Rab1 1 (S25N) and Cdc42 (T17N) were previously described (Hansen and Nelson, 2001; Gerges et al., 2004). In these constructs, EGFP is fused in frame at the $N$ terminus of the protein. For protein expression, all coding sequences (GluA1-EGFP, GluA2-EGFP, EGFP-Rab $11-D N$, and EGFP-Cdc42-DN) were cloned in pSinRep5 for the preparation of Sindbis virus. This is a neurotropic plus-strand RNA virus, which acts as an mRNA inside the cell, leading to high protein expression with low toxicity for $\leq 72 \mathrm{~h}$ after infection (Ehrengruber et al., 1999; Malinow et al., 2010). Protein expression was 36-48 h for GluA1-EGFP and GluA2-EGFP and 12-24 h for EGFP-Rab 11 -DN and EGFP-Cdc42-DN. Because only CAl cells (and not CA3 cells) were infected, this configuration ensured that recombinant proteins were always expressed exclusively in the postsynaptic cell.

\section{Cholesterol quantification}

LC/MS (Fig. 1 A). Hippocampal slices were rapidly washed in cold PBS and then homogenized in a lysis buffer containing $25 \mathrm{mM}$ MES, 2 mM EDTA, and cocktails of protease and phosphatase inhibitors from Roche. Typically, 10 slices were used for each experimental point. After centrifugation at $100,000 \mathrm{~g}$, both pellet fraction (containing mostly plasma membrane cholesterol) and supernatant (microsomal fraction containing mostly intracellular membranes) were analyzed separately. Lipid extraction and quantification of lipid phosphorus was performed as previously published (Bligh and Dyer, 1959; Rouser et al., 1970). In brief, tissue fractions are resuspended in a 1:2 mixture of chloroform/methanol. This is then diluted with a 1:1 mix of chloroform/water. After phase separation, the chloroform layer contains all lipids. Lipid phosphorus is then analyzed by two-dimensional thin-layer chromatographic separation of polar lipids and analysis of spots. Phospholipid content of cell extracts was determined by LC/MS on a mass spectrometer (4000-QTRAP; AB Sciex). Temperature was set to $475^{\circ} \mathrm{C}$, nebulizer gas was set to 60 at an inlet pressure of 5 bar, and a needle current was set to $1 \mu \mathrm{A}$. Declustering potential was set to $65 \mathrm{~V}$. Full scan spectra were collected in the range from 400 to 1,050 amu at a scan speed of $4,000 \mathrm{amu} / \mathrm{s}$. Relative response factors of lipid classes were determined using authentic standards as external calibrants (Brouwers et al., 2013). Cholesterol was analyzed essentially as described previously, using 4-cholesten-3-one as an internal standard (Brouwers et al., 2011). In brief, $5 \mu$ lipid extract, containing $\sim 250$ pmol cholesterol and 4-cholesten-3-one as an internal standard, was injected on a $50 \times 4.6-\mathrm{mm}$ hydrophilic interaction liquid chromatography column (Phenomenex) and eluted at a flow rate of $1 \mathrm{ml} / \mathrm{min}$. Thus separating free cholesterol from its esterified counterpart, free cholesterol was quantified by monitoring the transition from 369.3/161.1 amu and comparing its signal to that of the coeluting internal standard (transition 385.4/109.2 amu) with correction for their respective response factors and using a dwell time of $50 \mathrm{~ms}$.

For cLTP experiments, hippocampal slices were transferred for $5 \mathrm{~min}$ to a submersion-type holding chamber containing artificial cerebrospinal fluid (ACSF) gassed with $5 \% \mathrm{CO}_{2} / 95 \% \mathrm{O}_{2}$ at room temperature. For cLTP induction, slices were transferred for $15 \mathrm{~min}$ to a separate chamber containing $0.1 \mu \mathrm{M}$ Rolipram, $50 \mu \mathrm{M}$ Forskolin, and $100 \mu \mathrm{M}$ Picrotoxin in ACSF lacking $\mathrm{MgCl}_{2}$. After the induction period, some slices were transferred to a chamber containing regular ASCF, for a recovery period of $20 \mathrm{~min}$. After these treatments, slices were immediately homogenized and processed for cholesterol quantification.

Colorimetric assay (Fig. 2, A and B). Hippocampal slices were rapidly washed in cold PBS and then homogenized in a lysis buffer containing $25 \mathrm{mM}$ MES, 2 mM EDTA, and cocktails of protease and phosphatase inhibitors obtained from Roche. After suspension, samples were spun at $100,000 \mathrm{~g}$ for $2 \mathrm{~h}$ at $4^{\circ} \mathrm{C}$. Pellet (plasma membrane fraction, resuspended in PBS containing $0.1 \%$ SDS) and supernatant (microsomal fraction) were analyzed in parallel. Protein amount was quantified by Bradford Bicinchoninic Acid Assay kit obtained from Thermo Fisher Scientific, and the cholesterol content was measured per microgram of protein using the Amplex Red Cholesterol Assay kit obtained from Invitrogen.

\section{Fluorescence imaging for cholesterol quantification}

Organotypic hippocampal slices where either injected with $10 \mu \mathrm{M}$ Bodipycholesterol (provided by R. Bittman, City University of New York, New York, NY) and left incubating for 12-24 h to allow equilibration with endogenous cholesterol, or biolistically transfected ("gene gun") with mCherry-D4 and EGFP for $24 \mathrm{~h}$ to allow expression of the recombinant proteins. The mCherry-D4 plasmid was a gift from T. Kobayashi (RIKEN Advanced Science Institute, Saitama, Japan). Both mCherry-D4 and EGFP are expressed under the control of the cytomegalovirus promoter, using the pEGFP plasmid backbone from Takara Bio Inc. Confocal images were acquired with a confocal microscope (LSM510; Carl Zeiss) using a 63x, NA 1.2 water immersion objective and 488 - and $543-\mathrm{nm}$ lasers, at $29^{\circ} \mathrm{C}$. 
Fluorescence was collected as z stacks using Zen software (Carl Zeiss). For cLTP experiments, slices were perfused with ASCF. Baseline images were acquired every $5 \mathrm{~min}$ during $15 \mathrm{~min}$, and then, the perfusion solution was switched to ACSF containing $0.1 \mu \mathrm{M}$ Rolipram, $50 \mu \mathrm{M}$ Forskolin, and $100 \mu \mathrm{M}$ Picrotoxin, and without $\mathrm{MgCl}_{2}$. After a 15-min treatment, slices were perfused again with standard ACSF for a 10-min recovery period. For some slices, all perfusion solutions contained $100 \mu \mathrm{M}$ AP5 to block NMDARs. For Bodipy-cholesterol image quantification, regions of interest corresponding to individual dendrites were manually selected. For $m C h e r r y-D 4$ image quantification of the diffuse fraction, regions of interest were drawn in the soma. For mCherry-D4 cluster quantification, clusters were first defined by applying a threshold on images filtered with a Laplacian of Gaussian (LoG3D) plugin for ImageJ software (National Institutes of Health). The sum of integrated fluorescence intensity contained in these clusters was then quantified from the unfiltered images. All intensities were corrected for background signal. Images were reconstructed and analyzed using ImageJ software.

\section{Manipulations of cholesterol content}

Cholesterol removal. Organotypic slices were incubated for $30 \mathrm{~min}$ at room temperature in the dark with $10 \mathrm{U} / \mathrm{ml}$ Chol Ox (EMD Millipore) or $10 \mathrm{mM}$ MBCD (Sigma-Aldrich) in a submersion-type holding chamber containing

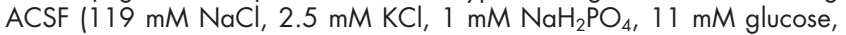
$26 \mathrm{mM} \mathrm{NaHCO} 3,4 \mathrm{mM} \mathrm{MgCl}$, and $4 \mathrm{mM} \mathrm{CaCl}$ ) gassed with $95 \%$ $\mathrm{O}_{2}$ and $5 \% \mathrm{CO}_{2}$. Control slices were incubated with ACSF alone (no vehicle control is needed because both Chol Ox and MBCD are dissolved in water). Some slices had a recovery period after treatment, by incubating them with ACSF alone for an additional $1 \mathrm{~h}$. Dissociated primary neuronal cultures were incubated with $10 \mathrm{U} / \mathrm{ml}$ Chol Ox or $10 \mathrm{mM} \mathrm{MBCD}$ in culture medium for $30 \mathrm{~min}$ at $37^{\circ} \mathrm{C}$. Controls were incubated with culture medium alone.

Cholesterol addition. Cholesterol-MBCD complexes were obtained by adding $30 \mu \mathrm{l}$ of $50-\mathrm{mg} / \mathrm{ml}$ cholesterol (Sigma-Aldrich) solubilized in a solution of methanol/chloroform 2:1 to $1 \mathrm{ml}$ of $50-\mathrm{mg} / \mathrm{ml} \mathrm{MBCD} \mathrm{dissolved}$ in water. The mixture was incubated at $80^{\circ} \mathrm{C}$ with shaking until clearance of the solution. Methanol, chloroform, and water were removed by speed vacuum overnight. The pellet was then resuspended in $20 \mathrm{ml} \mathrm{ACSF}$, and $20 \mu \mathrm{l}$ of $2-\mathrm{mg} / \mathrm{ml}$ cholesterol in $95 \%$ ethanol was added. This method is adapted from Klein et al. (1995).

\section{Electrophysiology}

Voltage-clamp whole-cell recordings were obtained from CA 1 pyramidal neurons under visual guidance using fluorescence and transmitted light illumination. The recording chamber was perfused with ACSF gassed with $5 \% \mathrm{CO}_{2} / 95 \% \mathrm{O}_{2}$, supplemented with $4 \mu \mathrm{M}$ 2-chloroadenosine, and maintained at $29^{\circ} \mathrm{C}$. Patch recording pipettes (3-8 MS) were filled with $115 \mathrm{mM}$ cesium methanesulfonate, $20 \mathrm{mM} \mathrm{CsCl}, 10 \mathrm{mM}$ Hepes, $2.5 \mathrm{mM}$ $\mathrm{MgCl}_{2}, 4 \mathrm{mM} \mathrm{Na}_{2}$ ATP, $0.4 \mathrm{mM} \mathrm{Na}_{3} \mathrm{GTP}, 10 \mathrm{mM}$ sodium phosphocreatine, and 0.6 mM EGTA, pH 7.25. For mIPSCs recordings, cesium methanesulfonate was replaced with the same concentration of $\mathrm{CsCl}$. For rectification experiments, the patch recording pipette solution was supplemented with $0.1 \mathrm{mM}$ spermine. Synaptic responses were evoked with single voltage pulses $(200 \mu \mathrm{s}, \leq 30 \mathrm{~V})$ on Schaffer collaterals. Responses were collected at $-60,+40$, or $0 \mathrm{mV}$, as indicated, and averaged over $50-80$ trials. AMPA/GABA ratios were obtained by evoking synaptic responses at -60 and $0 \mathrm{mV}$ holding potentials in the presence of the NMDAR antagonist AP5 $(100 \mu M)$. For NMDA/GABA ratios, recordings were performed in the absence of $\mathrm{Mg}^{2+}$ and in the presence of $10 \mu \mathrm{M} C N Q X$ (AMPAR antagonist), at $-60 \mathrm{mV}$ for NMDAR responses, and at $0 \mathrm{mV}$ for $G A B A_{A} R$ responses. For NMDAR time course, recordings were performed in the absence of $\mathrm{Mg}^{2+}$ and in the presence of $10 \mu M C N Q X$ and the $G A B A_{A} R$ antagonist picrotoxin $(100 \mu \mathrm{M})$. LTP was induced in CA1 neurons by pairing $3 \mathrm{~Hz}$ presynaptic stimulation of the Schaffer collaterals with $0 \mathrm{mV}$ postsynaptic depolarization. Recordings of miniature responses (mEPSC and mIPSC) were performed from 14-16 d in vitro hippocampal neurons at $-60 \mathrm{mV}$ in the presence of $1 \mu \mathrm{M}$ tetrodotoxin, $100 \mu \mathrm{M} \mathrm{AP5}$, and $100 \mu \mathrm{M}$ picrotoxin (for mEPSCs) or $10 \mu \mathrm{M} C N Q X$ (for mIPSCs). Electrophysiological recordings and data acquisition were performed with Multiclamp 700A/B amplifiers and pClamp software (Molecular Devices). Analysis was performed with pClamp software (miniature currents) or custom-made Excel (Microsoft) macros (supplemental material).

\section{Immunocytochemistry}

Neurons were fixed with $4 \%$ paraformaldehyde and $4 \%$ sucrose in PBS for $10 \mathrm{~min}$ at room temperature. Nonspecific binding was blocked with $0.2 \%$ gelatin in PBS for 30 min. For labeling surface GluAl, neurons were incubated for $1 \mathrm{~h}$ with an antibody against the GluR $1 \mathrm{~N}$ terminus (mouse monoclonal; Santa Cruz Biotechnology, Inc.). Total GluAl was then immunodetected after a permeabilization step (30-min incubation in $0.1 \%$ Triton $X-100$ and $0.2 \%$ gelatin in PBS) with an antibody against the GluR 1 C terminus (rabbit polyclonal; Abcam). Corresponding secondary antibodies (goat anti-mouse or goat anti-rabbit) conjugated with Alexa Fluor 488 and Alexa Fluor 555 (Life Technologies) were incubated for $45 \mathrm{~min}$. Coverslips were mounted in FluorSave reagent (EMD). Cells were imaged using an epifluorescence microscope (Axiovert 200; Carl Zeiss). Quantification was performed using ImageJ software. Regions of interest corresponding to individual dendrites were manually selected on the total GluA 1 channel. Therefore, image quantification was essentially blind with respect to the surface GluAl channel. All intensities were corrected for background labeling. For illustration of representative pictures (Fig. 3 B), image editing was performed using ImageJ and was limited to background subtraction and linear contrast enhancement.

\section{Protein biochemistry}

Slices were homogenized in a lysis buffer containing $10 \mathrm{mM}$ Hepes, $\mathrm{pH}$ 7.4, $150 \mathrm{mM} \mathrm{NaCl}, 10 \mathrm{mM}$ EDTA, $1 \%$ Triton X-100, and cocktails of protease and phosphatase inhibitors obtained from Roche (Complete Mini EDTA-free and phosSTOP). Protein amount was quantified by Bradford Bicinchoninic Acid Assay kit and analyzed by SDS-PAGE and Western blotting with an anti-GluAl antibody (rabbit polyclonal; Abcam) or antiCdc42 antibody (mouse monoclonal; BD). For the Cdc42 activation assay, GTP loading on Cdc42 was determined with a GST-Pak3-CRIB pull-down before Western blotting with the anti-Cdc42 antibody (Rodriguez-Fraticelli et al., 2010). Western blots were developed with chemiluminescence, and images were analyzed using Image software.

\section{Quantitative RT-PCR}

Total RNA from slices were extracted with TRIzol reagent (Ambion/Life Technologies) following the manufacturer's procedures and cleaned up using RNeasy Mini kit (QIAGEN). RNA was quantified by absorbance at $260 \mathrm{~nm}$ using a NanoDrop ND-100 (Themo Fisher Scientific). Retrotranscription to first-strand cDNA was performed using RevertAid H Minus First Strand cDNA Synthesis kit (Themo Fisher Scientific). In brief, 5 ng of synthesized cDNA was used to perform the quantitative PCR using GoTaq quantitative PCR Master Mix (Promega) in a sequence detection system (ABI PRISM 7900HT; Applied Biosystems; Life Technologies). The primers purchased from SigmaAldrich were used at $0.5 \mu \mathrm{M}$ final concentration to detect transcripts for Grin 1 forward, 5'-CCATTGTTCAAGAGGGTGCT-3', and reverse, 5'-GTCACTCCGTCCGCATACTT-3'; Grin2A forward, 5'-GCAAGCCACAGTATGCTGA-3'; and reverse, 5'-AGACGTGCCAGTCGTAGTCC-3'; and Grin2B forward, 5'-CCGAAGCTGGTGATAATCCT-3'; and reverse, 5'-ACCCTCTCCCACTTCCTCTC-3'. Three housekeeping genes Gapdh, GusB, and Pgk1 were used as endogenous controls.

mCherry-D4 and filipin imaging on human embryonic kidney (HEK) cells HEK cells were plated onto poly--lysine-coated coverslips and cultured at $37^{\circ} \mathrm{C}$ in DMEM (Gibco) supplemented with $10 \%$ of fetal bovine serum. Cells were transfected with mCherry-D4 plasmid using a calcium/phosphate protocol and let for protein expression during 12-24 h. For mCherry-D4 live imaging, cells were imaged in Tyrode's buffer $(30 \mathrm{mM}$ glucose, $120 \mathrm{mM}$ $\mathrm{NaCl}, 5 \mathrm{mM} \mathrm{KCl}, 2 \mathrm{mM} \mathrm{MgCl}$, $2 \mathrm{mM} \mathrm{CaCl}$, and $25 \mathrm{mM} \mathrm{Hepes)} \mathrm{with} \mathrm{a}$ confocal microscope (LSM510) using a 40x, NA 1.3 objective and 543-nm laser, at $25^{\circ} \mathrm{C}$. Images were reconstructed using ImageJ software. For filipin staining, cells were fixed with $4 \%$ paraformaldehyde and $4 \%$ sucrose in PBS, for $10 \mathrm{~min}$ at room temperature. Nonspecific binding was blocked with $0.2 \%$ horse serum (Gibco) in PBS for $30 \mathrm{~min}$. Cells were then incubated for $1.5 \mathrm{~h}$ with filipin (Sigma-Aldrich) at $50 \mu \mathrm{g} / \mathrm{\mu l}$ in the blocking solution. Coverslips were mounted in FluorSave reagent. Cells were imaged with a LSM510 confocal microscope using a 40x, NA 1.3 objective and 543-nm (mCherry) and 405-nm (filipin) lasers. Images were reconstructed using ImageJ software.

\section{MTT cell viability assay}

Slices were first incubated for $30 \mathrm{~min}$ at room temperature with Chol Ox or $\mathrm{MBCD}$ in ASCF as previously described. Slices were then incubated in ACSF with $5 \mathrm{mg} / \mathrm{ml}$ MTT (3-(4,5-dimethylthiazol-2-yl)-2,5-diphenyltetrazolium bromide) for $1.5 \mathrm{~h}$. Slices were then homogenized in DMSO, and cell viability was evaluated with the MTT reduction method, measuring the absorbance at $595 \mathrm{~nm}$ and subtracting background absorbance at $665 \mathrm{~nm}$, using a Microplate Reader (Model 550; Bio-Rad Laboratories). As a positive 
control for cell damage, some slices were incubated for $30 \mathrm{~min}$ with the indicated concentration of $\mathrm{H}_{2} \mathrm{O}_{2}$ (Fig. S2 C).

\section{Statistical analysis}

All graphs represent mean values \pm SEM. Statistical differences were calculated according to nonparametric tests. For pairwise comparisons, p-values were calculated according to two-tailed Mann-Whitney tests (for unpaired data) or Wilcoxon tests (for paired data). For multiple comparisons of cholesterol amounts (Fig. 1 A), Kruskal-Wallis tests were performed.

\section{Online supplemental material}

Fig. S1 shows representative HEK cells expressing mCherry-D4 and displays how D4 redistributes into aggregates upon cholesterol removal. Fig. S2 presents quantitative information, indicating that cholesterol reduction in hippocampal slices after treatment with Chol Ox or MBCD persists for $\geq 1 \mathrm{~h}$ after treatment. The source code for the analysis of the electrophysiological data is also available online in a Word file. Online supplemental material is available at http://www.jcb.org/cgi/content/full/jcb.201407122/ DC 1. Additional data are available in the JCB DataViewer at http://dx.doi .org/10.1083/jcb.201407122.dv.

We thank the personnel at the fluorescence microscopy facility of the Centro de Biología Molecular "Severo Ochoa" (Servicio de Microscopía Óptica y Confocal) for their expert technical assistance, and members of the Esteban laboratory for their critical reading of the manuscript. We also thank Robert Bittman for his gift of Bodipy-cholesterol and Toshihide Kobayashi for the cholesterol reporter mCherry-D4.

This work was supported by grants from the Spanish Ministry: SAF$2011-24730$ to J.A. Esteban, SAF20 10-14906 to C. G. Dotti, and CSD20 1000045 to both J.A. Esteban and C.G. Dotti. A. Brachet is supported by a Marie-Curie Intra-European Fellowship (FP7-PEOPLE-20 1 1-IEF No. 299864).

The authors declare no competing financial interests.

Author contributions: A. Brachet, C.G. Dotti, and J.A. Esteban designed research. A. Brachet carried out most of the experimental work and data analysis. S. Norwood helped with some of the biochemical and imaging experiments. J.F. Brouwers carried out LC/MS cholesterol quantifications, which were supervised by J.B. Helms. E. Palomer carried out mRNA quantifications and assisted with the cell viability assays. A. Brachet, C.G. Dotti, and J.A. Esteban wrote the paper

Submitted: 25 July 2014

Accepted: 27 January 2015

\section{References}

Abe, M., A. Makino, F. Hullin-Matsuda, K. Kamijo, Y. Ohno-Iwashita, K. Hanada, H. Mizuno, A. Miyawaki, and T. Kobayashi. 2012. A role for sphingomyelin-rich lipid domains in the accumulation of phosphatidylinositol4,5-bisphosphate to the cleavage furrow during cytokinesis. Mol. Cell. Biol. 32:1396-1407. http://dx.doi.org/10.1128/MCB.06113-11

Aoki, K., T. Nakamura, K. Fujikawa, and M. Matsuda. 2005. Local phosphatidylinositol 3,4,5-trisphosphate accumulation recruits Vav2 and Vav3 to activate $\mathrm{Rac} 1 / \mathrm{Cdc} 42$ and initiate neurite outgrowth in nerve growth factor-stimulated PC12 cells. Mol. Biol. Cell. 16:2207-2217. http://dx.doi .org/10.1091/mbc.E04-10-0904

Arendt, K.L., M. Benoist, A. Lario, J.E. Draffin, M. Muñoz, and J.A. Esteban. 2014. PTEN counteracts PIP3 upregulation in spines during NMDAreceptor-dependent long-term depression. J. Cell Sci. 127:5253-5260. http://dx.doi.org/10.1242/jcs.156554

Björkhem, I., and S. Meaney. 2004. Brain cholesterol: long secret life behind a barrier. Arterioscler. Thromb. Vasc. Biol. 24:806-815. http://dx.doi .org/10.1161/01.ATV.0000120374.59826.1b

Bligh, E.G., and W.J. Dyer. 1959. A rapid method of total lipid extraction and purification. Can. J. Biochem. Physiol. 37:911-917. http://dx.doi.org/10 $.1139 / 059-099$

Bliss, T.V., and G.L. Collingridge. 1993. A synaptic model of memory: longterm potentiation in the hippocampus. Nature. 361:31-39. http://dx.doi .org/10.1038/361031a0

Boehm, J., M.G. Kang, R.C. Johnson, J. Esteban, R.L. Huganir, and R. Malinow. 2006. Synaptic incorporation of AMPA receptors during LTP is controlled by a PKC phosphorylation site on GluR1. Neuron. 51:213-225. http://dx.doi.org/10.1016/j.neuron.2006.06.013

Brouwers, J.F., A. Boerke, P.F. Silva, N. Garcia-Gil, R.A. van Gestel, J.B. Helms, C.H. van de Lest, and B.M. Gadella. 2011. Mass spectrometric detection of cholesterol oxidation in bovine sperm. Biol. Reprod. 85:128 136. http://dx.doi.org/10.1095/biolreprod.111.091207

Brouwers, J.F., M. Aalberts, J.W. Jansen, G. van Niel, M.H. Wauben, T.A. Stout, J.B. Helms, and W. Stoorvogel. 2013. Distinct lipid compositions of two types of human prostasomes. Proteomics. 13:1660-1666. http://dx.doi .org/10.1002/pmic.201200348

Brown, T.C., S.S. Correia, C.N. Petrok, and J.A. Esteban. 2007. Functional compartmentalization of endosomal trafficking for the synaptic delivery of AMPA receptors during long-term potentiation. J. Neurosci. 27:1331113315. http://dx.doi.org/10.1523/JNEUROSCI.4258-07.2007

Caldeira, M.V., C.V. Melo, D.B. Pereira, R.F. Carvalho, A.L. Carvalho, and C.B. Duarte. 2007. BDNF regulates the expression and traffic of NMDA receptors in cultured hippocampal neurons. Mol. Cell. Neurosci. 35:208219. http://dx.doi.org/10.1016/j.mcn.2007.02.019

Christian, A.E., M.P. Haynes, M.C. Phillips, and G.H. Rothblat. 1997. Use of cyclodextrins for manipulating cellular cholesterol content. J. Lipid Res. 38:2264-2272.

Dart, C. 2010. Lipid microdomains and the regulation of ion channel function. J. Physiol. 588:3169-3178. http://dx.doi.org/10.1113/jphysiol.2010.191585

Deutsch, J.W., and R.B. Kelly. 1981. Lipids of synaptic vesicles: relevance to the mechanism of membrane fusion. Biochemistry. 20:378-385. http:// dx.doi.org/10.1021/bi00505a024

Dietschy, J.M., and S.D. Turley. 2004. Thematic review series: brain Lipids. Cholesterol metabolism in the central nervous system during early development and in the mature animal. J. Lipid Res. 45:1375-1397. http:// dx.doi.org/10.1194/jlr.R400004-JLR200

Ehrengruber, M.U., K. Lundstrom, C. Schweitzer, C. Heuss, S. Schlesinger, and B.H. Gähwiler. 1999. Recombinant Semliki Forest virus and Sindbis virus efficiently infect neurons in hippocampal slice cultures. Proc. Natl. Acad. Sci. USA. 96:7041-7046. http://dx.doi.org/10.1073/pnas.96 .12 .7041

Fessler, M.B., P.G. Arndt, S.C. Frasch, J.G. Lieber, C.A. Johnson, R.C. Murphy, J.A. Nick, D.L. Bratton, K.C. Malcolm, and G.S. Worthen. 2004. Lipid rafts regulate lipopolysaccharide-induced activation of $\mathrm{Cdc} 42$ and inflammatory functions of the human neutrophil. J. Biol. Chem. 279:3998939998. http://dx.doi.org/10.1074/jbc.M401080200

Frank, C., S. Rufini, V. Tancredi, R. Forcina, D. Grossi, and G. D’Arcangelo. 2008. Cholesterol depletion inhibits synaptic transmission and synaptic plasticity in rat hippocampus. Exp. Neurol. 212:407-414. http://dx.doi .org/10.1016/j.expneurol.2008.04.019

Gähwiler, B.H., M. Capogna, D. Debanne, R.A. McKinney, and S.M. Thompson. 1997. Organotypic slice cultures: a technique has come of age. Trends Neurosci. 20:471-477. http://dx.doi.org/10.1016/S0166-2236(97)01122-3

Gamba, P., G. Testa, B. Sottero, S. Gargiulo, G. Poli, and G. Leonarduzzi. 2012. The link between altered cholesterol metabolism and Alzheimer's disease. Ann. NY Acad. Sci. 1259:54-64. http://dx.doi.org/10.1111/j.17496632.2012.06513.x

Gerges, N.Z., D.S. Backos, and J.A. Esteban. 2004. Local control of AMPA receptor trafficking at the postsynaptic terminal by a small GTPase of the Rab family. J. Biol. Chem. 279:43870-43878. http://dx.doi.org/10.1074/ jbc.M404982200

Goslin, K., and G. Banker. 1989. Experimental observations on the development of polarity by hippocampal neurons in culture. J. Cell Biol. 108:15071516. http://dx.doi.org/10.1083/jcb.108.4.1507

Granger, A.J., Y. Shi, W. Lu, M. Cerpas, and R.A. Nicoll. 2013. LTP requires a reserve pool of glutamate receptors independent of subunit type. Nature. 493:495-500. http://dx.doi.org/10.1038/nature11775

Hansen, M.D., and W.J. Nelson. 2001. Serum-activated assembly and membrane translocation of an endogenous Rac1:effector complex. Curr. Biol. 11:356-360. http://dx.doi.org/10.1016/S0960-9822(01)00091-4

Hao, M., S.X. Lin, O.J. Karylowski, D. Wüstner, T.E. McGraw, and F.R. Maxfield. 2002. Vesicular and non-vesicular sterol transport in living cells. The endocytic recycling compartment is a major sterol storage organelle. J. Biol. Chem. 277:609-617. http://dx.doi.org/10.1074/jbc.M108861200

Hao, M., S. Mukherjee, Y. Sun, and F.R. Maxfield. 2004. Effects of cholesterol depletion and increased lipid unsaturation on the properties of endocytic membranes. J. Biol. Chem. 279:14171-14178. http://dx.doi.org/10.1074/ jbc.M309793200

Hayashi, Y., S.H. Shi, J.A. Esteban, A. Piccini, J.C. Poncer, and R. Malinow. 2000. Driving AMPA receptors into synapses by LTP and CaMKII: requirement for GluR1 and PDZ domain interaction. Science. 287:22622267. http://dx.doi.org/10.1126/science.287.5461.2262

Hering, H., C.C. Lin, and M. Sheng. 2003. Lipid rafts in the maintenance of synapses, dendritic spines, and surface AMPA receptor stability. J. Neurosci. 23:3262-3271.

Hölttä-Vuori, M., K. Tanhuanpää, W. Möbius, P. Somerharju, and E. Ikonen. 2002. Modulation of cellular cholesterol transport and homeostasis by 
Rab11. Mol. Biol. Cell. 13:3107-3122. http://dx.doi.org/10.1091/mbc .E02-01-0025

Hölttä-Vuori, M., R.L. Uronen, J. Repakova, E. Salonen, I. Vattulainen, P. Panula, Z. Li, R. Bittman, and E. Ikonen. 2008. BODIPY-cholesterol: a new tool to visualize sterol trafficking in living cells and organisms. Traffic. 9:1839-1849. http://dx.doi.org/10.1111/j.1600-0854.2008.00801.x

Hou, Q., Y. Huang, S. Amato, S.H. Snyder, R.L. Huganir, and H.Y. Man. 2008. Regulation of AMPA receptor localization in lipid rafts. Mol. Cell. Neurosci. 38:213-223. http://dx.doi.org/10.1016/j.men.2008.02.010

Huganir, R.L., and R.A. Nicoll. 2013. AMPARs and synaptic plasticity: the last 25 years. Neuron. 80:704-717. http://dx.doi.org/10.1016/j.neuron .2013 .10 .025

Jaksits, S., W. Bauer, E. Kriehuber, M. Zeyda, T.M. Stulnig, G. Stingl, E. Fiebiger, and D. Maurer. 2004. Lipid raft-associated GTPase signaling controls morphology and CD8+ T cell stimulatory capacity of human dendritic cells. J. Immunol. 173:1628-1639. http://dx.doi.org/10.4049/ jimmunol.173.3.1628

Kennedy, M.J., and M.D. Ehlers. 2006. Organelles and trafficking machinery for postsynaptic plasticity. Annu. Rev. Neurosci. 29:325-362. http://dx.doi .org/10.1146/annurev.neuro.29.051605.112808

Kim, I.H., H. Wang, S.H. Soderling, and R. Yasuda. 2014. Loss of Cdc42 leads to defects in synaptic plasticity and remote memory recall. eLife. 3:02839. http://dx.doi.org/10.7554/eLife.02839

Klein, U., G. Gimpl, and F. Fahrenholz. 1995. Alteration of the myometrial plasma membrane cholesterol content with $\beta$-cyclodextrin modulates the binding affinity of the oxytocin receptor. Biochemistry. 34:13784-13793. http://dx.doi.org/10.1021/bi00042a009

Kopec, C.D., B. Li, W. Wei, J. Boehm, and R. Malinow. 2006. Glutamate receptor exocytosis and spine enlargement during chemically induced long-term potentiation. J. Neurosci. 26:2000-2009. http://dx.doi.org/10 .1523/JNEUROSCI.3918-05.2006

Kotti, T.J., D.M. Ramirez, B.E. Pfeiffer, K.M. Huber, and D.W. Russell. 2006. Brain cholesterol turnover required for geranylgeraniol production and learning in mice. Proc. Natl. Acad. Sci. USA. 103:3869-3874. http://dx .doi.org/10.1073/pnas.0600316103

Lange, Y., M.H. Swaisgood, B.V. Ramos, and T.L. Steck. 1989. Plasma membranes contain half the phospholipid and $90 \%$ of the cholesterol and sphingomyelin in cultured human fibroblasts. J. Biol. Chem. 264:3786-3793.

Ledesma, M.D., and C.G. Dotti. 2006. Amyloid excess in Alzheimer's disease: what is cholesterol to be blamed for? FEBS Lett. 580:5525-5532. http:// dx.doi.org/10.1016/j.febslet.2006.06.038

Ledesma, M.D., M.G. Martin, and C.G. Dotti. 2012. Lipid changes in the aged brain: effect on synaptic function and neuronal survival. Prog. Lipid Res. 51:23-35. http://dx.doi.org/10.1016/j.plipres.2011.11.004

Linetti, A., A. Fratangeli, E. Taverna, P. Valnegri, M. Francolini, V. Cappello, M. Matteoli, M. Passafaro, and P. Rosa. 2010. Cholesterol reduction impairs exocytosis of synaptic vesicles. J. Cell Sci. 123:595-605. http:// dx.doi.org/10.1242/jcs.060681

Linsenbardt, A.J., A. Taylor, C.M. Emnett, J.J. Doherty, K. Krishnan, D.F. Covey, S.M. Paul, C.F. Zorumski, and S. Mennerick. 2014. Different oxysterols have opposing actions at N-methyl-D-aspartate receptors. Neuropharmacology. 85:232-242. http://dx.doi.org/10.1016/j.neuropharm.2014.05.027

Lippincott-Schwartz, J., and R.D. Phair. 2010. Lipids and cholesterol as regulators of traffic in the endomembrane system. Annu Rev Biophys. 39:559578. http://dx.doi.org/10.1146/annurev.biophys.093008.131357

Liu, L., T.P. Wong, M.F. Pozza, K. Lingenhoehl, Y. Wang, M. Sheng, Y.P. Auberson, and Y.T. Wang. 2004. Role of NMDA receptor subtypes in governing the direction of hippocampal synaptic plasticity. Science. 304: 1021-1024. http://dx.doi.org/10.1126/science.1096615

Malinow, R., and R.C. Malenka. 2002. AMPA receptor trafficking and synaptic plasticity. Annu. Rev. Neurosci. 25:103-126. http://dx.doi.org/10.1146/ annurev.neuro.25.112701.142758

Malinow, R., Y. Hayashi, M. Maletic-Savatic, S.H. Zaman, J.C. Poncer, S.H. Shi, J.A. Esteban, P. Osten, and K. Seidenman. 2010. Introduction of green fluorescent protein (GFP) into hippocampal neurons through viral infection. Cold Spring Harb Protoc. 2010:pdb.prot5406. http://dx.doi .org/10.1101/pdb.prot5406

Mans, R.A., N. Chowdhury, D. Cao, L.L. McMahon, and L. Li. 2010. Simvastatin enhances hippocampal long-term potentiation in C57BL/6 mice. Neuroscience. 166:435-444. http://dx.doi.org/10.1016/j.neuroscience.2009 .12 .062

Marks, D.L., R. Bittman, and R.E. Pagano. 2008. Use of Bodipy-labeled sphingolipid and cholesterol analogs to examine membrane microdomains in cells. Histochem. Cell Biol. 130:819-832. http://dx.doi.org/10.1007/ s00418-008-0509-5

Martin, M.G., S. Perga, L. Trovò, A. Rasola, P. Holm, T. Rantamäki, T. Harkany, E. Castrén, F. Chiara, and C.G. Dotti. 2008. Cholesterol loss enhances
TrkB signaling in hippocampal neurons aging in vitro. Mol. Biol. Cell. 19:2101-2112. http://dx.doi.org/10.1091/mbc.E07-09-0897

Martin, M.G., L. Trovò, S. Perga, A. Sadowska, A. Rasola, F. Chiara, and C.G. Dotti. 2011. Cyp46-mediated cholesterol loss promotes survival in stressed hippocampal neurons. Neurobiol. Aging. 32:933-943. http:// dx.doi.org/10.1016/j.neurobiolaging.2009.04.022

Martin, M.G., T. Ahmed, A. Korovaichuk, C. Venero, S.A. Menchón, I. Salas, S. Munck, O. Herreras, D. Balschun, and C.G. Dotti. 2014. Constitutive hippocampal cholesterol loss underlies poor cognition in old rodents. EMBO Mol. Med. 6:902-917. http://dx.doi.org/10.15252/emmm.201303711

Mayor, S., S. Sabharanjak, and F.R. Maxfield. 1998. Cholesterol-dependent retention of GPI-anchored proteins in endosomes. EMBO J. 17:4626-4638. http://dx.doi.org/10.1093/emboj/17.16.4626

Mercer, A.J., R.J. Szalewski, S.L. Jackman, M.J. Van Hook, and W.B. Thoreson. 2012. Regulation of presynaptic strength by controlling $\mathrm{Ca} 2+$ channel mobility: effects of cholesterol depletion on release at the cone ribbon synapse. J. Neurophysiol. 107:3468-3478. http://dx.doi.org/10.1152/ jn.00779.2011

Monyer, H., N. Burnashev, D.J. Laurie, B. Sakmann, and P.H. Seeburg. 1994. Developmental and regional expression in the rat brain and functional properties of four NMDA receptors. Neuron. 12:529-540. http://dx.doi .org/10.1016/0896-6273(94)90210-0

Murakoshi, H., H. Wang, and R. Yasuda. 2011. Local, persistent activation of Rho GTPases during plasticity of single dendritic spines. Nature. 472:100-104. http://dx.doi.org/10.1038/nature09823

Ohtani, Y., T. Irie, K. Uekama, K. Fukunaga, and J. Pitha. 1989. Differential effects of $\alpha$-, $\beta$ - and $\gamma$-cyclodextrins on human erythrocytes. Eur. J. Biochem. 186:17-22. http://dx.doi.org/10.1111/j.1432-1033.1989 .tb15171.x

Otmakhov, N., L. Khibnik, N. Otmakhova, S. Carpenter, S. Riahi, B. Asrican, and J. Lisman. 2004. Forskolin-induced LTP in the CA1 hippocampal region is NMDA receptor dependent. J. Neurophysiol. 91:1955-1962. http://dx.doi.org/10.1152/jn.00941.2003

Park, M., E.C. Penick, J.G. Edwards, J.A. Kauer, and M.D. Ehlers. 2004 Recycling endosomes supply AMPA receptors for LTP. Science. 305: 1972-1975. http://dx.doi.org/10.1126/science.1102026

Passafaro, M., V. Piëch, and M. Sheng. 2001. Subunit-specific temporal and spatial patterns of AMPA receptor exocytosis in hippocampal neurons. Nat. Neurosci. 4:917-926. http://dx.doi.org/10.1038/nn0901-917

Pfrieger, F.W. 2003. Cholesterol homeostasis and function in neurons of the central nervous system. Cell. Mol. Life Sci. 60:1158-1171.

Renner, M., D. Choquet, and A. Triller. 2009. Control of the postsynaptic membrane viscosity. J. Neurosci. 29:2926-2937. http://dx.doi.org/10.1523/ JNEUROSCI.4445-08.2009

Rodriguez-Fraticelli, A.E., S. Vergarajauregui, D.J. Eastburn, A. Datta, M.A. Alonso, K. Mostov, and F. Martín-Belmonte. 2010. The Cdc42 GEF Intersectin 2 controls mitotic spindle orientation to form the lumen during epithelial morphogenesis. J. Cell Biol. 189:725-738. http://dx.doi .org/10.1083/jcb.201002047

Rouser, G., S. Fkeischer, and A. Yamamoto. 1970. Two dimensional then layer chromatographic separation of polar lipids and determination of phospholipids by phosphorus analysis of spots. Lipids. 5:494-496. http://dx.doi .org/10.1007/BF02531316

Shepherd, J.D., and R.L. Huganir. 2007. The cell biology of synaptic plasticity: AMPA receptor trafficking. Annu. Rev. Cell Dev. Biol. 23:613-643. http://dx.doi.org/10.1146/annurev.cellbio.23.090506.123516

Shi, S., Y. Hayashi, J.A. Esteban, and R. Malinow. 2001. Subunit-specific rules governing AMPA receptor trafficking to synapses in hippocampal pyramidal neurons. Cell. 105:331-343. http://dx.doi.org/10.1016/S00928674(01)00321-X

Shimada, Y., M. Maruya, S. Iwashita, and Y. Ohno-Iwashita. 2002. The C-terminal domain of perfringolysin $\mathrm{O}$ is an essential cholesterol-binding unit targeting to cholesterol-rich microdomains. Eur. J. Biochem. 269:6195-6203. http://dx.doi.org/10.1046/j.1432-1033.2002.03338.x

Simons, K., and M.J. Gerl. 2010. Revitalizing membrane rafts: new tools and insights. Nat. Rev. Mol. Cell Biol. 11:688-699. http://dx.doi.org/10.1038/ nrm2977

Smith, A.J., S. Sugita, and M.P. Charlton. 2010. Cholesterol-dependent kinase activity regulates transmitter release from cerebellar synapses. J. Neurosci. 30:6116-6121. http://dx.doi.org/10.1523/JNEUROSCI.0170-10.2010

Sodero, A.O., L. Trovò, F. Iannilli, P. Van Veldhoven, C.G. Dotti, and M.G. Martin. 2011a. Regulation of tyrosine kinase B activity by the Cyp46/ cholesterol loss pathway in mature hippocampal neurons: relevance for neuronal survival under stress and in aging. J. Neurochem. 116:747-755. http://dx.doi.org/10.1111/j.1471-4159.2010.07079.x

Sodero, A.O., C. Weissmann, M.D. Ledesma, and C.G. Dotti. 2011b. Cellular stress from excitatory neurotransmission contributes to cholesterol loss 
in hippocampal neurons aging in vitro. Neurobiol. Aging. 32:1043-1053. http://dx.doi.org/10.1016/j.neurobiolaging.2010.06.001

Sodero, A.O., J. Vriens, D. Ghosh, D. Stegner, A. Brachet, M. Pallotto, M. Sassoè-Pognetto, J.F. Brouwers, J.B. Helms, B. Nieswandt, et al. 2012. Cholesterol loss during glutamate-mediated excitotoxicity. EMBO J. 31:1764-1773. http://dx.doi.org/10.1038/emboj.2012.31

Suzuki, R., H.A. Ferris, M.J. Chee, E. Maratos-Flier, and C.R. Kahn. 2013. Reduction of the cholesterol sensor SCAP in the brains of mice causes impaired synaptic transmission and altered cognitive function. PLoS Biol. 11:e1001532. http://dx.doi.org/10.1371/journal.pbio.1001532

Ullrich, O., S. Reinsch, S. Urbé, M. Zerial, and R.G. Parton. 1996. Rab11 regulates recycling through the pericentriolar recycling endosome. J. Cell Biol. 135:913-924. http://dx.doi.org/10.1083/jcb.135.4.913

Valenza, M., D. Rigamonti, D. Goffredo, C. Zuccato, S. Fenu, L. Jamot, A. Strand, A. Tarditi, B. Woodman, M. Racchi, et al. 2005. Dysfunction of the cholesterol biosynthetic pathway in Huntington's disease. J. Neurosci. 25:9932-9939. http://dx.doi.org/10.1523/JNEUROSCI.3355-05.2005

Valenza, M., V. Leoni, J.M. Karasinska, L. Petricca, J. Fan, J. Carroll, M.A. Pouladi, E. Fossale, H.P. Nguyen, O. Riess, et al. 2010. Cholesterol defect is marked across multiple rodent models of Huntington's disease and is manifest in astrocytes. J. Neurosci. 30:10844-10850. http://dx.doi .org/10.1523/JNEUROSCI.0917-10.2010

Xie, C., N. Li, Z.J. Chen, B.L. Li, and B.L. Song. 2011. The small GTPase Cdc42 interacts with Niemann-Pick C1-like 1 (NPC1L1) and controls its movement from endocytic recycling compartment to plasma membrane in a cholesterol-dependent manner. J. Biol. Chem. 286:35933-35942. http://dx.doi.org/10.1074/jbc.M111.270199

Zidovetzki, R., and I. Levitan. 2007. Use of cyclodextrins to manipulate plasma membrane cholesterol content: evidence, misconceptions and control strategies. Biochim. Biophys. Acta. 1768:1311-1324. http://dx.doi.org/10 .1016/j.bbamem.2007.03.026 